\title{
SELF-CONSCIOUS STORYTELLING AND THE CRISIS OF MASCULINITY IN EARLY ISHIGURO
}

BY

PATRICK MICHAEL MCKENZIE O’SULLIVAN

\author{
A thesis \\ submitted to the Victoria University of Wellington \\ in fulfilment of the requirements for the degree of \\ Master of Arts \\ In English Literature
}

Victoria University of Wellington 


\section{Acknowledgements}

I am indebted to my supervisor Adam Grener for how generous he has been in offering the support and guidance that brought this project to fruition. During a year in which global circumstances brought so many personal and professional challenges his understanding, knowledge, and hard work on my behalf was truly indispensable. I have learnt so much from him over the last two years.

I would also like to express my gratitude to my fellow research students in the English department for all their good humour, reassurance, and inspiration as we went through this process together.

I would like to thank the school administrator, Angelina Sbroma, for all her work and advice. Furthermore, I would like to thank the library staff for maintaining such a valuable resource for research, and would like to acknowledge and thank the cleaning staff who facilitated my working in an office space at the university.

Finally, I would like to acknowledge the part my girlfriend Sarah, my family, and my friends played in this thesis. It is only because they are the encouraging, faithful people they are that it was possible. I feel so lucky to have such a supportive partner as Sarah, who does not care about Kazuo Ishiguro, Mikhail Bakhtin, or Jacques Lacan, but on many occasions over the past year has pretended to for my gratification. Throughout this process she has been the most patient, loving, and encouraging partner.

A forever and lifelong thank you to my Mum and Dad, who filled our house with books and first lent me The Remains of the Day, and without whose influence and love this project is impossible to imagine. 


\section{Contents}

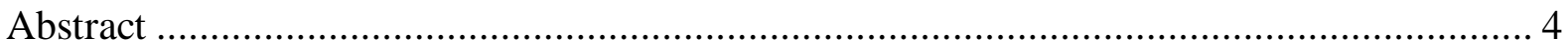

Introduction

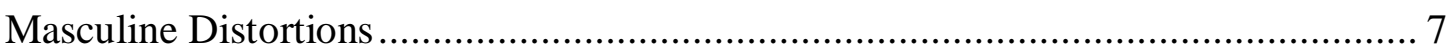

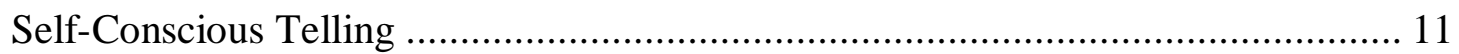

The Mirror Stage and the Storytelling Self ....................................................... 14

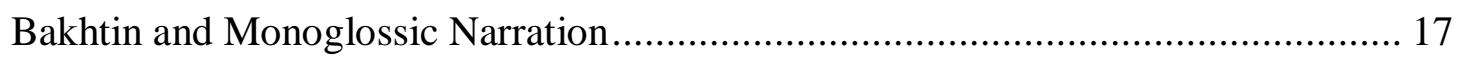

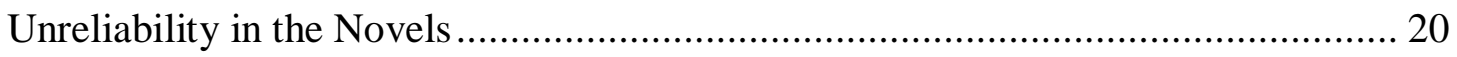

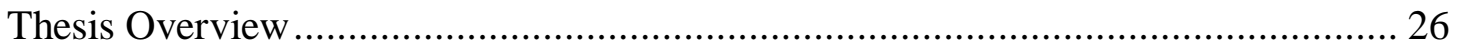

"My Artist's Eye": The Pattern-Making Crisis of An Artist of the Floating World .............. 28

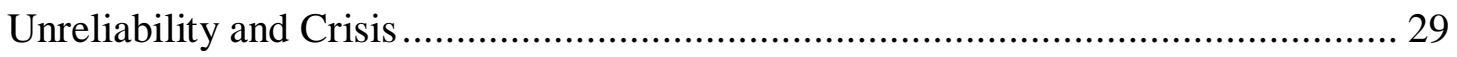

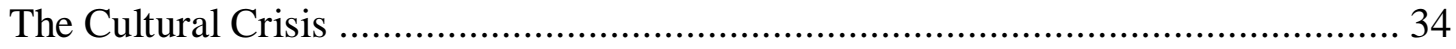

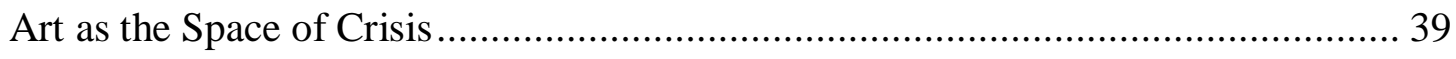

“The Professional Being": Expanding Narratorial Awareness and The Remains of the Day. 50

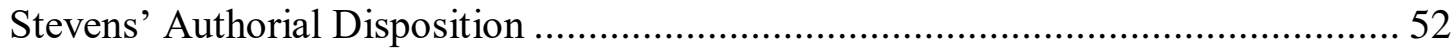

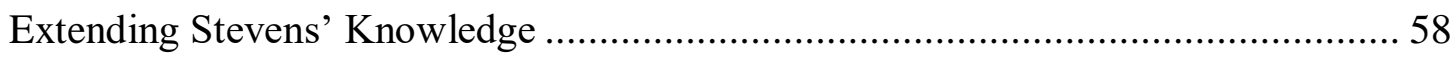

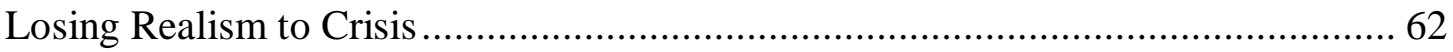

"Crushed Cadences": The Unconsoled and Controlling the Narrative ................................ 69

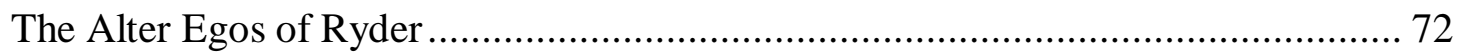

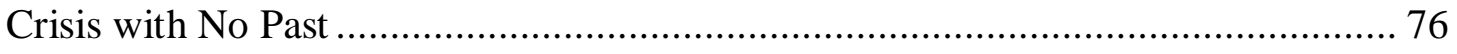

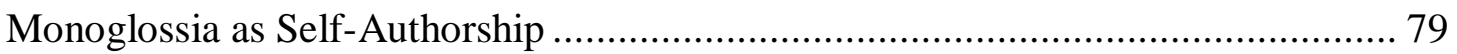

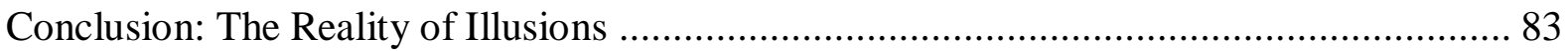

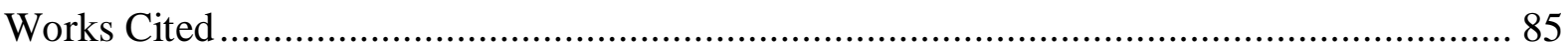




\section{Abstract}

This thesis engages with Kazuo Ishiguro's three novels, An Artist of the Floating World, The Remains of the Day, and The Unconsoled, as united by a common theme: the crisis of masculinity. These texts, written in succession from 1986 to 1995, are Ishiguro's first uses of male character narrators. This thesis takes this fact as consequential for the meaning of the works, as well as for the idea of their interconnection.

I link the obscured tragedies often identified in Ishiguro's narrators to the conflicting obligations they feel between their sense of themselves as men and their suppressed emotional lives. This imbalance between the private and public life is presented as a key conflict in Ishiguro's work, one accessed through identifying crises of masculinity. A crisis for Ishiguro is triggered by the realisation of the impossibility of balancing these two lives. Discussing how professional identity is tied to masculine identity, I analyse the way unreliability emerges from the overprioritising of work. I suggest that in this way identity performance is key to unreliable narration and that these narratives operate as a reorganisation of the narrators' biographies along the logic of crisis.

However, rather than suggesting that Ishiguro's true interest is on masculine crises, this thesis makes the case that by looking at this series of novels as different explorations of crisis, something new is revealed about the more documented interests of Ishiguro's experimentmemory, unreliability, history, and storytelling. Through this claim I seek to demonstrate how an overlooked aspect of Ishiguro's early work offers a fresh approach to his overall project. I combine established narratological analysis of the novels with this alternative perspective on the early works to analyse the way the author expands the bounds of readerly awareness, as well as the capabilities of narrators. In doing so I draw a causal chain between masculine crises, self-conscious narration, and violations of realism.

Each chapter explores the related ways Ishiguro carries his interest in crises of masculinity forward. The first, on An Artist of the Floating World, analyses the novel's sense of being self-consciously organised from within, expanding on the connection between a crisis of masculinity and authorial dispositions. The following chapter on The Remains of the Day takes up narratological theories on the implied author, the narratee, mimesis, and unreliability to examine the extent to which narrators can be aware of their unreliable narration's effects. The final chapter reads The Unconsoled as Ishiguro's "masterwork" on the crisis of masculinity. The chapter explores the ways the text acts as a heightening of the prior crisis novels to get a better grasp of this unusual work. 


\section{Introduction}

The reception of Kazuo Ishiguro's first novel presented the author with a specific reader response to which he reacts in his following works. The final, climactic scene of $A$ Pale View of Hills changes the meaning of prior events, and displays a sudden break in the apparent realism of the narrative. Ishiguro explains:

Yes, that scene in itself works all right, if the rest of the book had built up to that kind of ambiguity. But the trouble is that the backs are too clear, in a way. They seem to be related with the authority of some kind of realistic fiction. It doesn't have the same murkiness of someone trying to wade through their memories, trying to manipulate memories, as I would have wanted. The mode is wrong in those scenes of the past. They don't have the texture of memory. And for that reason the ending doesn't quite come off. It's just too sudden. I intended with that scene for the reader finally to realise, with a sense of inevitability, "Of course, yes, she's finally said it." Instead, it's a shock. (Mason 337-8)

Here the author describes how he sees his first novel as having failed to set up a totalising vision of a disturbed emotional life or a consistent illusion in which ambiguity does not come as a shock, but is seen as entirely natural, and in fact an inevitable consequence. In doing so he reveals what distinguishes the structuring principles of his next three works.

For his following novels Ishiguro seeks a method to develop the kind of ambiguity which comes suddenly at the end of A Pale View of Hills. This search is for a mode in which the manipulations of memory and the murkiness of the past riddle the story with uncertainty, where the reality of events is constantly problematised. In A Pale View of Hills many events and memories are made ambiguous, but largely retroactively, with the doubt introduced in the final scene. Ishiguro now pursues a "murkiness" throughout his narratives. What impedes this is that, as he says, "the backs are too clear": he has a problem with the "authority" of the realistic fiction with which he is associated, and his first novel's ending does not fully disrupt the overall impression of the text as a piece of realism. There is only an incident of lines blurring, rather than a portrayal of a storyteller's constant merging of imagination and the diegetic world of the novel's action. Thus, the ending is easily co-opted as within "the authority of some kind of realistic fiction." In his following projects, the room Ishiguro's storytelling narrators have to manipulate, obscure, and imagine will only expand, further and further from this authority. 
My argument in this thesis is that, in his search for a remedy to these issues in his subsequent works, Ishiguro lands on the phenomenon of the crisis of masculinity as the ideal way to embed the "texture of memory" as an essential characteristic of his narratives. This crisis is the fundamental difference between Etsuko and the type of narrator Ishiguro moves on to after her. In Ishiguro's following novels, all-encompassing crises cause narrators to not simply distort one element of their history, but to fundamentally reimagine their worlds. Etsuko may resort to unreliability to deal with her guilt, but the basis of her narration and its unreliability does not come as a result of the disconnection between her outward role in the world and her inner sense of herself. It is this conflict between the private and the public which makes up one essential basis of the "crisis of masculinity," and of the distortions in all three of Ishiguro's following novels from 1986 to 1995. Extreme identity performance leads to the reinvention not only of yourself, but the world beyond you as well.

In this way, Ishiguro uses masculine crisis to express many of his narrative concerns which go beyond it. I will argue that, as it is represented in Ishiguro, the crisis of masculinity is based on the attempt to overcome the impossible impasse between private, emotional demands, and those perceived from outside society. Often masculinities will experience crisis, in Ishiguro's rendition, when their view of themselves is not shared by the rest of their world. With his stated interest in setting up a space of possibility where the lines between a narrator's storytelling and the diegetic world are given more subtly, the distortions this crisis causes are the key to Ishiguro's imaginative project. The texture of memory is thus brought about, via the narrator's reimagining of the past and present to fit into his masculine crisis.

In this thesis I will be reading Ishiguro's works as an ongoing "experiment," in which later novels can be read as responses to those prior as regards Ishiguro's effort to refine certain technical and thematic elements. Ishiguro's interest in the technique of unreliability lends itself to this kind of interpretation. Working through his writing, the same themes show themselves again and again, and his different narrators, particularly across the period I look at here, come across as alternative approaches communicating a similar truth. Therefore, the argument of this thesis is that the unifying conflict in the novels from 1986 to 1995 is crises of masculinity, and Ishiguro uses this theme to explore his interest in storytelling, realism, and the imagination.

Peter Kemp's review in The Times called Never Let Me Go the final work of Ishiguro's "Bewilderment trilogy," completing what began in The Unconsoled and When We Were Orphans (Kemp). The reviewer suggests that the three are united by each being "riddled with mystery." This thesis devotes itself in part to making the case for a "Crisis 
trilogy," and furthermore, that it is through this holistic view that the overall meaning of Ishiguro's early work is made more explicable. In making this case for a "crisis trilogy," I will aim to draw out a persistent preoccupation with masculinity that unites these novels, but has largely been overlooked by critics. The aim of my argument is to demonstrate how crises of masculinity are the distorting vision of the world in Ishiguro's early novels which brings out so much about their multi-layered storytelling.

\section{Masculine distortions}

Masculinity here is the set of ideas which men associate with their identity as men. ${ }^{1}$ It is often viewed as unlike its binary opposite, femininity, in being an elusive status which must be earned, and as something tenuous which must be regularly displayed. Masculinity is essentially, therefore, a public role about display. As Alice Ferrebe observes, "though continually couched as rational, independent and isolated, masculinity as a project in fact involves an intense level both of emotional investment and of public performance and validation" (9). Much has been written on "precarious manhood," and psychological research has established the way in which this sense of precarity can reinforce the ideology behind and practice of traditional masculinity (Bosson $82-86) .^{2}$ The way in which I will discuss "crises" of masculinity stems from this feeling of precarity. Masculinity can become most dangerous when it is most vulnerable, and the stories examined here show its principles under a great deal of stress as characters cling to it while family or history leave them behind. These crises result from the inability to balance what bestows masculinity with what provides personal fulfilment. This balancing act can be between work and family or, more primitively, between outward duty and private emotions. Precarity is a focus for this thesis in understanding how first-person narration can be mobilised as a form of reassurance and to assuage feelings of fragility in narrators. Ishiguro's first three novels using male first-person narration, An Artist of the Floating World, The Remains of the Day, and The Unconsoled, all explore distinct causes for a crisis of masculinity. At the same time, they also reveal the common set of

\footnotetext{
${ }^{1}$ With this definition I do not mean to ignore the importance of "how feminism's critical interrogations of gender have productively disassembled the normative cultural discourse that weds masculinity to men and thinks about women only in the register of the feminine" (Weigman 33). Ishiguro's treatment of masculine crises is expressed using three male narrators, and this definition is based on their experience and interiorities. ${ }^{2}$ Alongside Bosson's "Precarious Manhood and Its Links to Action and Aggression," I am thinking of the studies by Robb Willer et al. on the "masculine overcompensation thesis." This sociological study looks at the way "that men react to masculinity threats with extreme demonstrations of masculinity" (980). See also the concept of "masculine imposture" in Friedlander (64).
} 
masculine preoccupations which run through the crises of all three narrators. More important than the commonalities of the crises themselves, however, are the similarities in the responses to crisis in each novel. Exploring narration as a tactic in this way reveals much about Ishiguro's approach to masculinity itself. Ishiguro, fascinated by illusions and the way they bleed into everyday, consensus reality, examines the continuing illusion of masculinity and its effect on first-person narration.

The idea of a "crisis of masculinity" is often approached as a historical phenomenon. In On Men: Masculinity in Crisis, Anthony Clare writes that "At the beginning of the twentyfirst century, it is difficult to avoid the conclusion that men are in trouble" (3). Clare presents this as the consequence of political developments, writing that principle among the causes for this alleged crisis is "the growing assertiveness of women. As a consequence of the feminist revolution, so this argument goes, women are no longer prepared to be the property of men... Men, like colonists seeing this empire crumble, don't like what's happening" (3-4).

Discussions of masculinity in crisis do have this association with writing about the perception that men, relative to earlier privileges in areas such as work, family, and education, are losing power. The sense of shifting political expectations around masculinity is relevant to the examination of historical settings in this research, but this thesis is more concerned with looking at Ishiguro's representation of a second kind of crisis, one far less easily documented. This is a set of internal crises, perhaps related to wider political events, but much more personal. In Cultures of Masculinity, Tim Edwards writes about a crisis along these lines, which “centres precisely on a perceived shift in men's experiences of their position as men, their maleness, and what it means. Most importantly, this often refers to a sense of powerlessness, meaninglessness or uncertainty" (8). These novels centre on moments of historical importance - most notably in their explorations of the consequences of World War Two-but what is most relevant to my argument here is the way each narrator's focus is not on anything of great magnitude, but instead on his own smaller field of duties and respectability. Everything is scaled down to the level of internal crises. Though the narrators' crises involve this navigation between the public world and their private experience, the true roots of each crisis are gradually revealed as even more individual than is first apparent. The outward, historical crisis in masculinity, in which men's purpose, value, and justification are under widespread scrutiny is a useful concept when discussing novels such as An Artist of the Floating World, where Ono's traditional patriarchal role is threatened in post-war Japan.

However, to the extent that this thesis discusses real-world movements, it is largely limited to examining the way in which this prompts the second kind of internal crisis. 
This does not mean my reading seeks to diminish the way in which masculinity as practiced by individuals both in and outside of fiction reproduces social attitudes and is a product of political movements. After all, "Masculinities come into existence at particular times and places, and are always subject to change. Masculinities are, in a word, historical” (Connell 185). But it does mean that rather than suggesting that each of these novels propagates the idea that their historical settings resulted in an age of crisis for men, this thesis argues that each novel looks at one specific crisis for one man. In fact, in cases where the rest of the world does appear to be in crisis, this may be a result of it being represented through a narrator's distorting view. Unreliability in the texts is therefore connected to analysing how crisis can arise out of fragility or trauma. This understanding allows for a more expansive set of associations with unreliability, and I see it as a much more humanising avenue through which to explain why narrators communicate misleading information to their audience.

In Ishiguro, the crisis of masculinity is a psychological phenomenon in which the character is overwhelmed by the sense of impossibility of balancing the contradictory demands of the private emotional life and the demands to perform masculinity outwardly. The demands of masculinity are often related to a career, or another means of establishing reputation. For instance, Ono's crisis involves his feeling that he contributed to the death of his wife and son through his making a name for himself propagating military expansionism and war. By trying to be a man he has failed as a father, and so his crisis emerges as an overwhelming realisation of the cost of him overprioritising masculinity. Unreliable narration in the novels is often focussed on obscuring this immense cost and preserving the masculine illusion. The distortions of the novels are an effort to make this cost coherent; the violations of realism twisting the world into a universe in which the narrators' actions make sense, where masculinity, or art, or butlering, or piano, are really as important as they felt.

Often masculine crises are driving the narrators not to actively deceive via unreliability, but to instead withhold information even from their own consciousness. There is an inability to admit the truth even to themselves. Their compromised view of "what really happened" is a general condition of first-person narration, but, in the case of the narrators examined here, it is specifically informed by a kind of masculinity which means they are denying or revising events in a specific way to assuage feelings of fragility. As a practice of unreliability it is a way to cope. The argument of this thesis is therefore that the kind of precarity and fragility which appear throughout Ishiguro's novels serve functions which are inseparably both formal and thematic. 
The novels' very narration is therefore a location of crisis. These crises can each be traced back to a principle commonly associated with masculinity. For Ono this is reputation, for Stevens it is duty, and for Ryder, responsibility. The crises are much more individualised than these broad principles, but they are the terms in which each man has staked his claim to masculinity. Ishiguro's iterative novel-writing process is detectable here, where we can see different approaches in representing crisis as the root of a type of storytelling. Ishiguro searches for the limits of crisis as a logic of organising narrative. In each case control is shown to be a fixation for the narrators, and Ishiguro uses first-person narration as a means of communicating and practicing this drive to control. The world is fundamentally misaligned with the narrator's view of himself. He then misrepresents the world in his narration as a means of exercising control and assuaging his crisis. These crises share many common elements in terms of emotional repression, but their most striking similarity in form is this: they each arise out of the narrator's subconscious realisation that he constructs his reality subjectively, alongside the simultaneous realisation that historical forces external from him are impossible to fit into the contours of his crisis.

Masculinity within Ishiguro's novels has received a small amount of attention. Feminist commentaries do exist, most commonly of A Pale View of Hills and of The Remains of the Day, with Stevens' relationship with Miss Kenton eliciting particular interest. Linda Raphael writes of "the play between masculine and feminine discourse" in the way Stevens buys into myths of nation and history, while Miss Kenton's feminine discourse remains nonmythical (172). Perhaps most directly related to this work is Alice Ferrebe's chapter on masculinity in the contemporary male-authored novel, containing an extensive analysis of The Remains of the Day and Stevens' role as masculine narrator. Ferrebe takes the opposite view from Raphael, arguing that "the novel does not seek to uphold women as an antidote to masculine emotional repression or unreliable narration" (158). Although these gender-based analyses of Ishiguro's work seem most applicable in setting up the literary background to this thesis, these studies are, naturally, most often focussed on gender in and of itself as a structuring principle behind narrative. The case above, for example, in which a key conflict in The Remains of the Day is identified as being between Miss Kenton's feminine discourse and Stevens' masculine. It is pertinent to state here that although this thesis relies on concepts and work done within the field, it is not itself a work of gender narratology.

However, these concepts of a "masculine discourse" and "masculine... unreliable narration" that Ferrebe analyses are some of the foundational concepts of my thesis. Beyond providing a vocabulary and critical landscape to launch from, the main debt this thesis owes 
to this field in general is the formulation of masculinity as about identity. Masculinity, as I have come to understand through researching these scholars, is a site for the complex negotiation between self and other. The essential insight I gain from the work cited here is the perspective of masculinity as a story told by a culture which restructures and reprioritises one's interior world. A popular understanding of masculinity might lead one to believe that it is purely a very expressive, action-packed concept or behaviour, about the desire to destroy others, to exert power. While the way I identify masculine crises in these novels often does involve an attempt at mastery through language, what I take from interacting with these texts is the extent to which this conflict expresses itself internally. My own contribution to an analysis of gender in Ishiguro is finding the place of masculine aspects of power or control in the anxious, quiet, guilty personalities of these three narrators. These figures by the time of their narratives are not very active as characters, but nevertheless masculinity signifies a crushing pressure on all three of them, and specifically on how they talk about themselves.

\section{Self-conscious Telling}

This understanding of masculinity is in one way very personal, but in being so also foregrounds the tensions between the individual and the wider society to which they belong. Ishiguro explains his focus here,

I am interested in storytelling in the sense of what a community or a nation tells itself about its past and by implication therefore where it is at the moment and what it should be doing next. If you want to draw a parallel between how individuals come to terms with their past and decide what to do next, and how a nation or a community approaches such things, then the issue of storytelling is an important one. (qtd. in Bizzini 67)

Ishiguro raises many of the central dynamics of this thesis: the individual and the collective, history, and storytelling. Storytelling for Ishiguro can therefore be read as an act carried out by an individual or community in order to build a coherence and connection from past to present. For characters in the midst of crisis, and particularly those who take up their storytelling role as a way of dealing with their crisis, this must first be resolved in order for this myth of history as progressive to be viable. What this resolution means is particular to each character and individual crisis of masculinity, but similarities are shared especially in each narrators' approach to their role of storyteller. 
This reading of Ishiguro's first-person novels sees their narration as inherently divided, and as arising from the divided self's confrontation with crisis. Unreliability makes us aware of the internal rivalry between different versions of the self (the image trying to be created in narration versus the reality), a rivalry often resulting from the awareness of an audience. In becoming conscious of this internal discord, readerly attention is elevated beyond or behind the story itself and on to the story of the story. Thus, Stevens' tale seems to be about his journey through England to meet an old colleague, but this is made background to the real subject: Stevens' awareness of how he is seen by others and seen by his new self. Unreliable narration is the device used to communicate this truer focus, in which Stevens betrays not only his real preoccupations, but also his eagerness to have the narrative be something quite different from what it ends up being. In this sense he, and all of these narrators, humanise themselves at the same time as drawing focus onto the narrative's use of techniques (and their purely fictional existence). From a narratological perspective, then, we can see how Ishiguro's narrators are constructed simultaneously as sympathetic, human storytellers, and as synthetic devices. The authorial audience's focus shifts from the story that is being told onto the processes that have caused the narration to operate the way that it does and that have called the narrator to his role.

This state of affairs can be said to be a tension inherent in unreliability. By definition unreliability draws the reader's attention to the artificiality of the text (the pretences of the story world, how characters are constructed). At the same time, however, unreliability generally, and in Ishiguro's case in particular, is a means of emphasising the complexity and humanity of a character through their flaws. One of the characteristic aspects of Ishiguro's approach to unreliability is his negotiation of this tension - unreliability's drive to cultivate both artificiality and mimesis. ${ }^{3}$ However, narration here carries this tension to a further degree. For this trilogy, it is not simply that unreliability as a technique brings attention to the

\footnotetext{
${ }^{3}$ The distinction James Phelan, whose work will be discussed later in this chapter, draws between estranging and bonding unreliability relates to this point. Bonding/estranging similarly depends on the consequences of unreliable narration for the relationship between that narrator and the authorial audience. However, Phelan's contrast is based on the authorial audience recognising that in adopting the narrator's perspective they could be moving away from the implied author's. There is no further mimesis-breaking element here. The alternative is not between exposing the author's artifice versus sustaining their illusion. However, I bring up Phelan's concept here for its explanation of how readerly sympathy interacts with the narrative communication model. Phelan, in explaining his estranging-bonding distinction, uses The Remains of the Day and Stevens by way of example, and his analysis goes: "When Stevens writes at the end of The Remains of the Day that 'in bantering lies the key to human warmth,' he is underregarding because he does not see that human warmth depends on much more than bantering. Nevertheless, the statement shows that Stevens has learned something in the course of the narrative, has moved closer to Ishiguro's ethical beliefs" ("Estranging" 225). To Phelan, there is a bonding going on within this case of underreporting. In my own examination of the presence of crisis in unreliable narrators, sympathy can be similarly elicited from the psychological pain unreliability can imply.
} 
synthetic nature of a narrator's role; the narrators themselves are in the grip of such anxiety over their role as storytellers that they give their stories another layer of artificiality. Their crises of masculinity mean they are quite consciously trying to accomplish something with their narration, and therefore find themselves talking about it, and their role.

In this respect these narrators' artificiality, their turning the pointing finger away from events and onto themselves as storytellers, is another instance of Ishiguro's humanising process. The very fictionality of it, the distortion of a life into a narrative, furthers the illusions of these characters seeming real. The recounting of the past through narrative organisation gives these narrators the chance to put a narrative order over the important moments of their lives, and to place crisis-causing instances of the past within the unifying body of a coherent storyline. Self-authorship and unreliability amount to these narrators denying their crisis, and distorting its causes. Through the crisis and its resulting effects on narration, Ishiguro draws attention to what is going on within narration itself, shifting readerly focus on to how a narrator got into his situation and why he narrates from the position he does. So, events do not simply occur, they are organised. Within these universes of crisis, no occurrence can be seen to simply drop out of the sky, because the crisis is constantly intimating how events have been placed where they are via the conscious process of narration.

Although there is no scholarship on Ishiguro looking directly at the crisis of masculinity, themes of alienation and uncertain sense of self can be found in several works consulted through this thesis, and the topic fans out into other areas of scholarship. Much of the critical work on Ishiguro's novels has been focussed on either his interest in memory, or upon the status of his work as international literature. Within these studies on Ishiguro and the place of his work in the world, there is a general division: the first, and more popular, variety sees his work as adjacent to a postcolonial project to build an international literature. Malcolm Bradbury, for example, writes that Ishiguro's fiction marries "British with other forms of fiction to create an international, late-modern fictional voice that is... larger than any individual culture" (425). Alternatively, critics have framed Ishiguro's geographical contributions by analysing the "Japaneseness" of his novels (Suter 5). This emphasis on the significance of Ishiguro's country of birth is more commonly a response to his first two novels, both set in Japan. Cynthia Wong recounts how, "If early reviewers admire Japanese attributes of the young writer, they also peg Ishiguro as a foreign writer who just happens to write in the English language" (8). Ishiguro himself has written that: 
My very lack of authority and lack of knowledge about Japan, I think, forced me into a position of using my imagination, and also of thinking of myself as a kind of homeless writer. I had no obvious social role, because I wasn't a very English Englishman, and I wasn't a very Japanese Japanese either. (Ōe 115) I go into more detail on this line of criticism because these international studies, which emphasise the uprooted, alienated, and detached existences the narrators experience, accentuate a different kind of crisis for these characters, while sharing a common theme with my own research. In this literature there can also be found a consistent cause of anxiety and psychological burden for the narrators, proposing a useful focus on the displacement of these narrators which compliments my reading. ${ }^{4}$ This thesis draws on this literature to argue that the crisis of masculinity helps to better understand the alienation Ishiguro's narrators feel from their surroundings. My addition to their research is the following: that although both $A n$ Artist of the Floating World and The Remains of the Day have vivid settings, when paired with The Unconsoled's absence of any true setting or location, Ishiguro's true "geographic" focus becomes clear: the imaginary and lonely country within.

\section{The Mirror Stage and the Storytelling Self}

To help us better understand the implications of Ishiguro's redirection of attention onto fictionality, I will draw on the theoretical writings of Jacques Lacan and Mikhail Bakhtin. First, Lacan's concept of the mirror stage can help illuminate the reading of selfauthorship as I have already described it. In simple terms, the mirror stage is the point in a person's infancy at which they can identify their reflection in a mirror as corresponding to them. Lacan hypothesises that this recognition occurs before a proper sense of motor coordination over one's body is developed. His concept is therefore that there is a fundamental division at the root of a person's ego felt between the "I" seen in the mirror, appearing as a whole image, and the "I" of the direct experience of lack of coordinationbetween the seeing self and the image self. One's first experience of oneself as a social being,

\footnotetext{
${ }^{4}$ Under this theme of Ishiguro's international writing many contributions have been made. For instance Wong herself with "Ishiguro as an International Writer." But perhaps most relevant to my thesis is Chu-Chueh Cheng's book on the paradoxes revealed in Ishiguro's work through studying the significance of marginality to the novels. She once again takes the novels as a body, and her observations of how internationalism is connected to otherness in Ishiguro provide a useful framework for my own research. In doing so she connects the alienation I describe here as emerging out of masculine crises to the crisis of place that these writers see as more central.
} 
via the image, therefore arrives with the emergence of a rivalry between the complete picture seen in the mirror and the subject seeing it. A symmetry between the two selves is prevented by the completeness of the image accentuating the subject's lack. The subject is made to think of the figure in the mirror as 'them,' but in the image there appears no resemblance with the internal world of the seeing self. In order to resolve this crisis, the subject chooses to identify with the complete image, who they have told $i s$ who they are. In this way Lacan suggests the mirror stage as the genesis of the ego, through identification with the counterpart. The psychoanalyst and translator of Lacan, Bruce Fink explains the process in the following way:

Once internalized, these various images fuse, in a manner of speaking, into a vast global image which the child comes to take for him or her self; this self-image can, of course, be added to in the course of a child's life, new images being grafted upon the old. In general, it is this crystallization of images which allows for a coherent 'sense of self' (or does not allow for it in cases in which the images are too contradictory to fuse in any way), and a great deal of our attempt to 'make sense' of the world around us involves juxtaposing what we see and hear with this internalized self-image: How does what happens reflect upon us? Where do we fit in? Is it a challenge to our view of ourselves? (37)

I provide this long explanation in full as it sets out the basis of my connection between Lacan and Ishiguro. Fink's emphasis on the disunited self draws out the usefulness of Lacan to these studies of narrators' psychologies and the final string of questions sums up what the narrators are seeking to answer through their novels. The internalisation Fink describes produces two central aspects of Ishiguro's crises of masculinity: alienation and narcissism. The conceptual importance of Lacan's theory here lies with the negotiation, and in fact the masculine rivalry, between what lies within and what lies without. The representation of oneself as being competent and in control is in fact creating more tension with the seeing self of direct experience full of inadequacies.

In applying this psychoanalytic theory to narration, I draw on Anna Koustinoudi's case of how the relationship

of the subject to its mirror image also permeates the structures of narrative and hence the narrative "I" in any given text since narratives, as products of linguistic/discursive practices, are deeply embedded in and informed by the same ideological formations as those upon which human subjectivity is predicated. (6) 
Stevens and his absolute sense of his delimited role in society demonstrates how this framework can be applied to a crisis of masculinity. ${ }^{5}$ Lacan uses the mirror stage to express how "the function of the ego is... one of misrecognition; of refusing to accept the truth of fragmentation and alienation" (Homer 25). This refusal is the heart of the unreliability in the novels analysed here, perhaps of Stevens in particular. Stevens, upon reflecting on his past, is presented with two prospects: the self of direct emotional experience, where he has lost his chance at love and wasted much of his life in a misguided pursuit, or the self as the image of the traditional English butler, who foregoes an emotional life for one of service. Via narration he chooses at first to identify with the image of himself as a butler, as Lord Darlington might have seen him. In this realm he gains an authority to speak on the sources of achievement that this role values - dignity and withholding of emotion. He achieves instant access to his status as man. The Remains of the Day in this reading is a story of how Stevens begins to come to terms with his seeing self and register the ways in which his identification with the image was a misrecognition, or at least a recognition of only a very limited version of himself. Unreliability is therefore a symptom of crisis, and Stevens underreports in order to come across as the man he sometimes wishes he could truly be.

Lacan's theory can be taken further when transposed onto the method of narration itself. Stevens in this reading uses narration to reflect on his own status as narrator. This reflection foregrounds the distinctive feature of Ishiguro's narrators of this period from many other first-person narrators. There is a heightened sense of the 'scene' of storytelling in these novels. Through the assumption of the role of narrator these characters try to become the one who is seen, rather than the active one who is seeing. This gap between the two dimensions of "I" is foundational to the crisis of masculinity, explaining the role of these storytellers as both narratorial and character presences. The goal becomes to turn oneself into the whole, unified body seen in the mirror through the presentation of oneself as important in narration. This is a situation only made more impossible by the fragmented body this denial of the seeing self creates.

Rather than a literal mirror prompting this recognition, the mirror stage viewed more abstractedly only requires the observation of observed or reproduced behaviour. Within the

\footnotetext{
${ }^{5}$ Molly Westerman also applies Lacan's theory to Stevens by way of Homi K. Bhabha's concept of "stereotype." Bhabha develops his theory of the specific discourse of stereotype based on Lacan's more general theory: "Like the mirror phase 'the fulness' of the stereotype —its image as identity—is always threatened by lack," and, because it is "a form of splitting and multiple belief, the stereotype requires, for its successful signification, a continual and repetitive chain of other stereotypes" (Bhabha 77). Westerman uses these theories to interrogate Stevens' attempt to achieve "fixity of meaning" by stereotyping himself, turning himself into an image for other to easily receive (Westerman 163).
} 
metaphor of the child recognising itself, this could be noticing how one imitates gestures from others, but within the framework of Ishiguro's novels history provides this context. In these novels, the past is the mirror through which each narrator recognises and conceptualizes his image. Corresponding with this, the narrators will consistently distort their memory and the past. This is both personal history in the form of immediate memory, and communal history in the way in which World War II provides a backdrop against which these narrators must tactically recount their memories. Through the reinterpretation of the past via narrators' storytelling, history ceases to be prior direct experience, and begins to act as formulation of the image, complementing the crisis-enforcing narrative. Narrative memories are not just a recounting of the past, but are used to draw a meaningful connection between then and now. They express the need to re-enter one's past life experiences as a way of dealing with one's present life. Storytelling, narration in the style seen here, transforms this into an attempt to reconcile the image with the seeing self. And this is the great insight of Lacan in the mirror stage that is relevant for my thesis: human social relations involve this performance or aspiration towards appearing whole in the eyes of others - in other words, that there is a storytelling aspect essential in our presentation before others. It also reveals the contradictory place of history in Ishiguro's work: it operates as both a cause behind the creation of and identification with the image, while also carrying resolutory power in holding within it another view of the narrator. Lacan's formulation thus provides an extremely useful line of thinking when applied to Ishiguro's narrators, though my use of it remains in this conceptual respect, viewing it as a kind of trope.

\section{Bakhtin and Monoglossic Narration}

Lacan's work contributes to this thesis in illuminating how the self is a construct of others, and relies on the affirmation of others. The work of literary critic and linguist Mikhail Bakhtin similarly explores the significance of language as a communal force, and something which cannot operate in isolation. This thesis approaches his work and linguistic concepts in a similar conceptual way to the above approach to Lacan. Bakhtin explains how the language and dialogue of a novel emerge from a historical process, that all language use is riddled with many voices ("voices" in a broad sense of discourses, perspectives, ideologies). He gives the name "heteroglossia" to the process he identifies through which a single language, such as in a novel, reflects a diversity of languages, which each present their own experience. Bakhtin formulates this theory as the correct way to approach a text's or language's process of 
meaning-making; his fundamental understanding being that "the language of a novel is the system of its "languages"” (Bakhtin 262). In this way Bakhtin views the essence of dialogue as its simultaneous ability to differentiate multiple voices, while also fusing them to present a unity (Bakhtin 264). There are multiple participants in a conversation, but they work to maintain a single system of understanding.

Bakhtin as a philosopher of language and linguist applies heteroglossia in terms of a real historical evolution of language and something traceable in style. In my application of it to narration, I am transposing Bakhtin's structure and applying it to narration within the storyworld, thinking of an ethos of heteroglossia against an ethos of monoglossia. The way in which the multivocality of character dialogue is set in opposition to a single-voiced monologue is the aspect of Bakhtin's theory most useful here because it helps to illuminate the dynamics of these narrators' crises and their drive to control a narrative. My reading of heteroglossia as an ideology or worldview in this thesis builds on insights of Leslie Baxter who has suggested that, "Bakhtin's life work can be understood as a critique of the monologisation of the human experience that he perceived in the dominant linguistic, literary, philosophical, and political theories of his time" (102 Baxter). This thesis works with this spirit of monologisation, rather than a concrete linguistic concept. The idea of a singular voice in conflict with a multi-languaged worldview is effectively transferred onto dynamics within a story world. Bakhtin's description of language quoted here in fact lends itself to this reading: "We are taking language not as a system of abstract grammatical categories, but rather language conceived as ideologically saturated, language as a world view, even as a concrete opinion" (Dialogic Imagination 271).

The reconstruction of history through memory in these novels, and the hostility with which narrators build their own version of events against outside alternatives, makes these narrators special cases in exemplifying the threat the narrator can pose to the diverse language of a novel. A worldview governed by monoglossia, then, is a crisis stemming from a drive to control, and manifested in narration as an effort to exert singular authority over the story told to the narratee and authorial audience. It is this condition which characterises the mindset of all three narrators at the opening of their narratives, and constitutes a misguided attempt to control their crises. ${ }^{6}$

\footnotetext{
${ }^{6}$ Adriana Neagu uses a Bakhtinian reading of The Remains of the Day to draw a similar conclusion about the monglossic nature of the novel. She contrasts Bakhtin's view of the novel as "a social engaged space" with "the carefully controlled unity of Ishiguro's texts, marked by the limited character freedom and the solemn, 'high seriousness' mode Bakhtin associated with the epic form" (277). Neagu thus concludes that, "Ishiguro writes poems in prose... The poematic symphonism of Ishiguro's prose is too unitary to be novelistic" (270). Seonjoo
} 
Just as the novel arose out of an "intimate interaction (both peaceful and hostile)" with living rhetorical genres (journalistic, moral, philosophical) and artistic genres (epic, dramatic, lyric), so too do languages within a single novel arise from a similar historical dialogue and interplay of languages (Dialogic Imagination 269). This concept of history as a dialogising force promoting the heteroglossic nature of a text can be applied within a text as well, with history viewed as the means through which other voices enter the novel. It is this process which is behind the contradictory space history and memory occupy in the exacerbation/resolution of crisis. Narrators are prompted to enter into and rewrite their past as it plays a central role in their crisis of masculinity (Ono's feeling of powerlessness over the post-war world, for example). They initially use their memories to complement their image. But in doing so they show their hand as storytellers (Ono's complicity in wartime atrocities inevitably exposed), and it becomes clear that guilt over these past errors was behind both their crisis and their re-examination of memory in the first place.

Reapplying the concepts of Lacan and Bakhtin to narration more abstractly thus helps to direct and structure my approach to how storytelling relates to the crisis behind narration in Ishiguro's work. Bakhtin's concepts are useful in drawing a connection between the context time/history provide and for how these narrators interact and interpret other characters. Heteroglossia's use as a term here is a conceptual approach for the way in which Ishiguro's narrators attempt to dominate the transmission of truth in these novels. ${ }^{7}$

Bakhtin provides a conceptual framework with which to examine the narrators' representations of their outside world and its effect on them, while Lacan provides a theory through which the internal origins of the crisis can be traced. The importance of both theories lies in their addressing the processes which cause the narrators to narrate in the way that they do - why the story is being told in the way that it is. The theories demonstrate the particular way Ishiguro uses his narrators as storytellers that link the construction of identity to their fragmented memory process in an attempt to recover from a haunting past. Reading the novels in light of both of these theories positions the narrators as careful readers of their own

Park uses Bakhtin's theory of the dialogic to argue that, "Bakhtin's attempt to renew literature by reconceptualising 'the novel' as a genre is exactly in line with Ishiguro's career-long search for a new type of fiction that loosens the tie between literature and national culture" (46).

${ }^{7}$ Lynda Broughton argues that the subject position which makes itself opposed to heteroglossia is typical of the phallic male "I". In Broughton's analysis, the very construction of masculinity relies upon the singular, unifying imagery of the phallus: "The phallus, literal or otherwise, thus becomes a metaphor for the self: it is the letter "I", the number one, the singular, unique subject of its own discourse and the story of "I" displaces all other stories in a single, privileged act of writing - the construction of the subject" (139). Her case is relevant for the way Ishiguro's male narrators try to rewrite their diegetic worlds around their own psychological concerns. 
lives, they become storytellers employing what strategies they can to present their best selfportrait.

\section{Unreliability in the Novels}

It has become a matter of course to describe Ishiguro's narrators from this period and through all his novels as unreliable. ${ }^{8}$ This thesis will be rehearsing the rhetorical approach to unreliability of James Phelan, finding his emphasis on the indirect lines of communication involved in character narration especially relevant. In a thesis in which I make claims about expanding our conception of narrators' awareness over their narratives, this conception is especially useful. Most of the material drawn from Phelan here comes from his book Living to Tell About It on ethics and character narration, which specifically analyses The Remains of the Day. This thesis suggests that a focus on the crisis of masculinity offers new dimensions in understanding Ishiguro's use of unreliability to the broader study of rhetorical narrative theory.

The three novels examined here are each biographies or origin stories of a narrator's crisis, communicated through suggestion and understatement. All three also show narrators' attempts to grapple with their own unreliable memories and interpretations, tracing the damage or confusion this failure has caused in their past. The narratives investigate the motivations behind someone arriving at their mistaken conclusions about themselves and the world, and show these characters undergoing the same investigation. Unreliable narration is Ishiguro's mechanism of choice to draw the audience's attention to the traumatised psychology of the narrator, and to trace back the motives of this unreliability. Ishiguro's focus is on unreliability as a subject of psychological disclosure, a way to uncover the true preoccupations of the narrator. His narrators fall into a type which Kathleen Wall describes as, "the narrator whose weakness is psychological, who lies to or hides from himself, whose subjectivity is a sight of so much conflict that he or she finds it necessary to bracket off large portions of his or her experience, or who has a huge emotional investment in a certain view of things, else the metaphysical blocks of his world will come tumbling about his head" (21). On the axis of facts and events these narrators appear to have occasional lapses which implicate the stability of the rest of the narrative, but are largely trustworthy, at least in

\footnotetext{
${ }^{8}$ Cynthia F. Wong writes that "Stevens is simultaneously as unreliable and as sympathetic a narrator as either Etsuko or Ono" (52-3). For Rebecca L. Walkowitz "That familiar category, 'unreliable narrator,' would seem to characterise the first person protagonist in every one of Ishiguro's five novels to date" (1067).
} 
comparison to their interpretations of facts or their positions on the axes of perception and of evaluation. As it happens, we take their version of the facts of scenes to be true precisely because of how they naively expose their own anxieties in their telling, and thus their deficient perceptions or mistaken evaluations.

It is these interpretations or responses to factual scenes through An Artist of the Floating World, Remains of the Day, and The Unconsoled which offer a way to recognise unreliability. This is done through interpreting the narrators' commentary or emotional response as they describe it. For instance, the first time Ono visits his old friend Matsuda partway through his novel he reveals no signs of distress in his narration. He portrays the meeting as simply two men remembering their youth together with nostalgia. Only in their second meeting, at the very end of the novel, does Matsuda reveal the true nature of Ono's mood on the previous occasion as "very disillusioned" (200). This absence of emotional commentary, allowing his aloof telling of factual events to give a misleading impression, is typical of Ono's unreliability. Actions such as this place Ono into Wall's category of a narrator who "bracket[s] off large portions of his or her experience." Ono's narration is not factually inaccurate, but it is insufficient, and in being so it conceals or transforms the true meaning of events. Here Ono underreports, but he does so because of a disproportionate sense of guilt and mistaken values; as a result, he misevaluates as well. His coexistence on these different axes is central to the acting out of masculine crisis, and a key reading experience prompted is the discovery that his underreporting comes from his misevaluating. This is the state of affairs which also describes much of Stevens' narration through The Remains of the Day. This second narrator in crisis over his masculinity finds himself unable to communicate the truth behind his physical journey from the beginning of the novel. Stevens' attributing the cause of the narrative, his trip to visit Miss Kenton, to pure professional motives is eventually understood as another example of underreporting and "bracketing off" resulting from a misevaluation of what brings his life value (emotional connection, not brutal personal sacrifice in the pursuit of masculine values).

Likewise, both narrators preface their memories with commentary which they clearly feel is required to give the narratee a kind of 'corrected' context before they are exposed to the memory. In doing so, they continually expose their own knowledge that the actions about to be relayed disagree with present day norms, and with the image they have tried to portray. For example, when Ono describes his early meeting with Matsuda as a young man, the occasion in which he began to be converted by his friend into a propagandist for imperialist militarism, he makes sure to mention how, "most of our earlier meetings would end with our 
becoming extremely antagonistic towards one another" (169). In the scene that follows, Matsuda argues how, "It's time for us to forge an empire as powerful and wealthy as those of the British and the French. We must use our strength to expand abroad. The time is now well due for Japan to take her rightful place amongst the world powers" (174). On such occasions, the implied author communicates using the audience's knowledge of history to show how mistaken Ono and Matsuda are. Yet, the narrative is organised as Ono's realisation of the ways he has failed. Thus, the present-day Ono joins with the authorial audience and implied author in looking back at the Ono of the past and feeling the distance between past and present. There is a distance, not just between our own cultural codes and that of the unreliable narrator, but also between the unreliable narrator's past, revealed through memory, and the current narratorly perspective. Ono has achieved some awareness over the moments of significance and of delusion in his past. In moments such as these, Ishiguro uses Ono's reading of his own life to try to get ahead of the reader's judgement in some way; to intercept the implied author's communication with the audience - or at least to displace it a degree further. In doing so he identifies Ono as a character partly responsible for and aware of the judgement. Lacan's concept of the divided self is useful to keep in mind here-Ono tries to reconstruct himself as the complete image through narration.

Another location where unreliability is exposed is the way each narrator structures the narrative around his crisis. The psychological preoccupations Wall describes become clear to the audience as they consistently resurface in specific moments, placed alongside specific scenes and memories. Narrative order becomes a key piece in the narrator's communication of his masculine crisis. For example, Ono will respond to his reputation being questioned in the narrative with a deliberately placed memory in which he is celebrated. In doing so he exposes his anxiety about reputation. For Stevens, we read his descriptions of his sense of "triumph" over his professional command of an evening's work, despite his personal tragedy. Even for Ryder the motives behind his narration become somewhat clearer as any evocation of family causes a relatively normal scene to twist away into distortions. It is this structure which intimates the narrators' view of the full poetry of their life building up to their crisis, and what creates the sense of them as "storytellers." In the case studies explored in the following chapters, this sense of structure of each novel is important in examining how Ishiguro uses his storytelling narrators to expand the bounds of the reader's awareness. This is built not only from the theories of Lacan and Bakhtin I described above, but also previous Ishiguro scholarship. James Phelan asks whether Stevens might be "a consummate storyteller whose ability to build to a climax is comparable to Ishiguro's" (Living 36). Silvia Caporale 
Bizzini similarly looks at the way Ishiguro uses the storytelling theories of Hanna Arendt and Walter Benjamin to construct the telling roles of his narrators and to examine the idea of, as her title puts it, "narrators as storytellers." 9

There is a distinction to be made here between what I have been calling the narrator's "storytelling," or shaping of the narrative of their lives, and the devices of the author. I would argue that the audience receives the narrator as ordering elements of their history into patterns, which can blend into the form of the novel (the diary pretence of Artist and Remains, for instance). While it is conventional in criticism to view the patterns that emerge in first-person narration as a synthetic dimension of the text - that is, as a product of the implied author - the dynamics of Ishiguro's first-person narrators invite us to view the narrators themselves as participants in the pattern-making structure of narration. The novels reflect self-consciously on pattern-making in storytelling using the narrators. However, it is of course the author deploying the character of a first-person narrator who creates these patterns in their life using later reflections. Thus, the author ensures that the reader becomes aware that they are engaging with a particular type of narrator who is searching for meaning in his life, and who is aware of his role as storyteller.

Ishiguro seems to be trying to use his characters' preoccupations with their crises to sharpen readerly awareness, and create a more perceptive reading in which the control the narrator has over the narrative becomes unclear. The demand is for the reader to recognise how information is being communicated in alternate ways. This thesis makes the case that the demand to expand awareness is tied to the masculine crisis, and it is the masculine crisis which calls for other forms of narratorial communication. Crises of masculinity are ostensibly muffling, silencing phenomena (trauma cannot be spoken of, it shatters the masculine image), but in being so they demand ulterior lines of communication. The reader is on the lookout for ways the truth can slip through, by monitoring the very process through which the narrator communicates. Most of the scholarship I will draw on through this thesis is related to concepts in narratology. Critics such as Wall, Phelan, and Elke D'hoker have all helped to

\footnotetext{
${ }^{9}$ In Nausea, Sartre writes, "a man is always a teller of stories, he lives surrounded by his own stories and those of other people, he sees everything that happens to him in terms of these stories and he tries to live his life as if he were recounting it" (64). Oliver Sacks holds that, "each of us constructs and lives a "narrative" and that "this narrative is us, our identities" (110). Marya Schechtman suggests a person "creates his identity [only] by forming an autobiographical narrative - a story of his life" (93). Finally, Dan Dennett claims that: "we are all virtuoso novelists, who find ourselves engaged in all sorts of behaviour, and we always try to put the best 'faces' on it we can. We try to make all of our material cohere into a single good story. And that story is our autobiography. The chief fictional character at the centre of that autobiography is one's self' (22). Here I argue that Ishiguro's novels on masculine crisis depict representations of this human impulse to think about our lives and our selves as though they were narratives.
} 
establish the primary dynamics of unreliability in Ishiguro's novels, even as my focus on unreliability through the lens of masculine crises helps us to see some less-examined aspects of the novels.

This widening prompts the question of how unreliability shifts the relationship between story and discourse in a narrative. Using Shlomith Rimmon-Kenan's distinction, “"story' designates the narrated events, abstracted from their disposition in the text [discourse], and reconstructed in their chronological order" (3). Seymour Chatman explains how unreliability is revealed through the narrator's erroneous discourse being undermined by the story, as the implied author communicates through the distance between the two (Coming to Terms 233). Yet the discourses analysed in this thesis are constructed using the logic of a distorting crisis, with the narrator oftentimes obscuring any kind of 'true' chronological story through means of commentary, narrative order, and his various other acts of unreliability.

How are we to reconstruct any story when the discourse, as it unfolds, not only misplaces the significance of facts, but denies or erases them? This process is most pronounced in The Unconsoled, where we begin to get an idea of what is happening in Ryder's mind, but are never sure to what extent this is occurring in his physical reality as well. In Ishiguro's previous novels there are more certain historical landmarks that the crisis of each narrator can be traced back to, but as each story unfolds and the effect of crisis on narration reveals itself, Ryder's narration becomes differentiated from those prior more by degree than kind. In examining the dynamics of unreliability in Ono and Stevens' narration in terms of masculine crisis, I want to suggest that they create a precedent for understanding and interpreting Ryder's more extreme distortions.

Ishiguro has said of Christopher Banks, the narrator of When We Were Orphans, that his unreliability is unconventional in that it does not allow the reader to "measure the distance between his craziness and the proper world out there... a lot of the time the world actually adopts the craziness of his logic" (qtd. in Holmes 14). This is of course even more strongly true of Ryder's narration, in which there at times appears to be no "world out there" beyond Ryder's own personal history and projected future. Ishiguro identifies this as "craziness," but also makes the point that there is no position of sanity provided in the novels through which to measure this. The absence of this gauge on reality is felt most in The Unconsoled, but the point is that the same logic runs through all of Ishiguro's work as iterations on one another, resulting from a shared crisis.

An Artist of the Floating World and The Remains of the Day have a much more immediately accessible real world against which to measure. The reader is familiar with the 
historical context when Matsuda expresses the need for Japanese supremacy in Asia, or Lord Darlington praises Mussolini and Hitler. The case I am making for The Unconsoled, however, has repercussions for these earlier novels, and in fact shakes the authority of realism within them as well. The ambiguities more constantly present in Ishiguro's final addition to his crisis trilogy help in understanding how the ambiguities present in the prior novels place all events within a realm where emotions (crises) prevail over a shared reality. The Unconsoled reveals how these are essentially novels about the reality of illusions, biographies of a hidden inner life of emotional experience.

Technically, this has to do with what Brian Richardson calls the "ontological fragility of the status of much fictional discourse" (94). The way unreliability impedes a cohesive story is important for the approach taken here to the divided self of the narrator-storyteller. As we see through these novels, "at any point, the narrator can contradict what has been written, and thereby transform the entire relationship between events" (Richardson 94). This fragility caused by unreliability in the discourse/story relationship corresponds with the fragility in the narrator's identity as an image. The image relies upon the difficulty in constructing a story out of narrated events as it is an ahistorical projection, at odds with the retrievable story, and based instead on the narrator's priorities of crisis (such as art, dignity, or music). Indeterminability of the story becomes the foundation of the conflict between monoglossia and heteroglossia explained earlier. With the difficulty of discerning story, "All that is left for the narratologist to work with is the discourse, since all we know is the sequence in which the dubious events are presented or negated. At this point, a fundamental distinction at the foundation of modern narrative theory breaks down" (Richardson 94).

Scholarship on The Unconsoled warrants particular note, as the critical writing on this novel is often in significant contrast to literature looking at other pieces of Ishiguro's work, or his work overall. ${ }^{10}$ Critics will often refer to Kafka's influence on the novel, and in relation to this, the significance dreaming seems to have on its logic. ${ }^{11}$ Almost all scholarship on The Unconsoled considers the difficulty of identifying the text. Its striking difference from Ishiguro's first three novels, typically interpreted as largely straightforwardly realist, is also frequently a subject of critical attention. As I have made reference to already, part of my own

\footnotetext{
${ }^{10}$ Frederick Holmes, for example, looks at the unconscious in The Unconsoled, the way the novel goes about digging up obscured feelings. Cynthia Wong's study similarly looks directly at its difficulty and the way it avoids comprehension. Studies such as Gary Adelman's base their analysis on the initial negative reaction to the novel.

${ }^{11}$ Robert Lemon explains how “critics agree that Ishiguro's novel possesses broadly Kafkaesque characteristics, such as indeterminate setting, a dream-like tone, and the absence of a conventional narrative resolution" (207).
} 
project in response to this is recuperating this novel as very much existing within Ishiguro's general points of attention and interest. Thus, while The Unconsoled has been seen as a departure from Ishiguro's earlier works, particularly in the way it abandons both place and time, this thesis reads The Unconsoled as a recognisable continuation of Ishiguro's traditional interests. This reading raises the question of how the novel's apparent senselessness gains further coherence in light of the prior novels, and concurrently, how these previous novels lose their strict sense of realism in light of The Unconsoled.

\section{Thesis Overview}

This thesis is structured around close readings of a sequence of three novels from 1986 to 1995. I isolate these as signifying a distinct trilogy within Ishiguro's work in which he explores particular themes and plays with methods of unreliability. I structure the chapters around these three novels in chronological order. These case studies focus on the specific approaches to masculine crisis in each novel, while making the case for their iterative nature. Just as the trilogy examined here has been set up as a response to A Pale View of Hills, many of the techniques surrounding unreliability and storytelling through the crisis of masculinity are gathered over the progress of this trilogy, and culminate in The Unconsoled.

The first chapter, on An Artist of the Floating World, analyses the novel as filled with patterns and sequences which work as an alternate way for the character narrator to communicate his crisis. Ono uses his artistic powers to tell the story of his crisis, and in doing so begins the trend which follows of narratives which feel designed from within themselves. Ishiguro creates narrators who are readers of their own lives, and are conscious of the way they are read by others. The connection I draw through this chapter and carry on into the following, is viewing masculinity as a collection of stories told to maintain the self, and unreliability as a natural language to express this. In An Artist of the Floating World, Ishiguro first plays with the idea of unreliable narration as involving the conjuring up of alternate versions of events as though they were alternate universes, coexisting with no clear resolution as to what truly occurred

The second chapter, on The Remains of the Day, continues the previous chapter's focus on examining the extent to which the narrators act as their own "authors." An Artist of the Floating World and The Remains of the Day share both similar strategies of unreliability, and historical settings. However, this second chapter takes a more technical angle from the first, looking at relevant work done in the field of narratology more directly. Ideas of the 
implied author and mimesis are more central for this chapter, as it seeks to make a further claim about the awareness of Ishiguro's narrators as self-aware communicators. The influence of James Phelan's rhetorical theory of narrative is felt most directly in this chapter, and central to my argument is his distinction between the mimetic, synthetic, and thematic elements making up a narrative. The previous chapter establishes the way the crisis of masculinity embeds itself in the overall architecture of a narrative. This chapter makes a narratological argument for a similar expansion of Stevens' awareness of the effects of his narration.

Through these first case studies, a pattern is established of narrators in the grip of masculine crisis trying to claim control over their narratives. The final chapter of the thesis, on The Unconsoled, brings together threads established in the prior chapters to demonstrate the arc of this trilogy. The readings of the other novels are used as a point of access for making sense of this highly unusual novel. Ishiguro uses the overloaded psychology of Ryder to elevate characteristics of the previous novels, now superimposing the distortions of crisis onto the physical world. The final chapter explores the heightening of techniques to argue that this dynamic in fact reveals the true meaning of the prior novels - that these things were already "real." This chapter focuses on the extent to which masculine crisis leads narrators to create a private world of delusions, over which they have ultimate control. Bakhtin's work features heavily in this last chapter, as I identify how narrators attempt to assert their control and masculinity through monoglossia. The real significance of discussing these works as a trilogy is best understood here-An Artist of the Floating World and The Remains of the Day not only help to make sense of The Unconsoled, but this final novel also gives the reader new information about its forebears.

\section{"My Artist's Eye": The Pattern-Making Crisis of $A n$ Artist of the Floating World}

Quietly the fusion took place, and everything fell into order, into the pattern of branches that I have woven throughout this memoir with the express purpose of having the ripe fruit fall at the right moment...

- Vladimir Nabokov, Lolita 
In her book of feminist narratology Plotting Women: Gender and Narration in the Eighteenth-and Nineteenth-Century British Novel, Alison Case explains the meaning behind the terms "feminine" and "masculine" narration of that period. For Case, a feminine narrator acts much like a feminine woman of eighteenth- and nineteenth-century Britain was expected to, not "preaching," governing, or steering (4). A feminine narrator records experience, without shaping it toward particular ends. Meanwhile, this leaves "masculine narrators" to be "artful" or manipulate through plot as they desire (37). Masculine narrators are character narrators who actively shape the designs of their narratives. The distinction Case explores in $18^{\text {th }}$ and $19^{\text {th }}$ century novels reveals something of the impact of masculinity, and of masculine crises, in contemporary novels as well. Masculine crisis asserts itself through control of a narrative, and the narration of Masuji Ono in An Artist of the Floating World is gendered in the same fashion as his crisis. He commits himself to an assiduously designed narrative, and Ono's artfully arranged life story fits into the binary Case identifies perfectly. This chapter seeks to unravel the deeply laid pattern of symbols within Ono's narration which correspond to his crisis. Although the nature of his masculine narration in Case's sense is in some ways subtle, what can be found at the centre of this maze is a carefully arranged means of dealing with a crisis of masculinity.

In Ishiguro's first novel to use a male first-person narrator he makes his focus the intersection between history and the individual. An Artist of the Floating World approaches the fallout of World War II in Japan in a detached and indirect way, similar to the treatment of the bombing of Nagasaki in A Pale View of Hills. But here the lines between an individual subjective crisis of one masculinity and a whole nation or world in crisis following the horrors of war become more blurred. Ono's shaken sense of himself as a man has implications not just for his own unreliable narration, but for a whole world working through tragedies similar to his own. This narrator is put in the position of writing not just for himself, but for many others in similar positions. Ono was a famous painter before the war, and his role as an artist is central to his narration and to the meaning of the novel in general. It is from this role that he interprets the lives of others.

Although Ono's crisis of masculinity corresponds to an individual emotional life, $A n$ Artist of the Floating World presents a way in which such subjectivity can speak to a shared tragedy. In this way Ono's unreliability as a narrator, and in fact his crisis of masculinity itself, speaks to a personal situation that extends well beyond one man. The number of 
resonances and repetitions through the novel results in the full meaning of events remaining hidden until some way into the novel. This chapter proceeds through the novel, almost tallying up the reoccurring images and pieces of dialogue. The sections are divided into an introduction to the way unreliability is connected to crisis from the very beginning of the novel, the way Ono's personal crisis of masculinity is associated or conflated with a broader cultural crisis, and, finally, how Ono's unreliable narration of this world, and the synchronicities mentioned call back to his status as an artist, making a claim about the essential storytelling component within the crisis of masculinity. Crises of masculinity force their carriers to take alternate routes to communicate their pain, and in this novel we see one such route is through narrative organisation.

\section{Unreliability and Crisis}

As I noted in the introduction, Ono's masculine crisis results from a sense of powerlessness. He is powerless to stop the changes his country is undergoing, and most importantly proves powerless to protect his family. Connecting both of these is Ono's powerlessness to preserve his reputation in post-war Japan. An Artist of the Floating World is a novel told through memory, and it is this focus on past and present reputation which is the reader's introductory access point into the narrator's mind and into his unreliable narration. The novel's opening scene establishes Ono's method as a narrator-a method in which the tragedy motivating his concealments is revealed obliquely through his effort to reassert his reputation in the face of this growing powerlessness. The reputation-based memory with which the novel begins, therefore, is not just to be read as exposition in which we learn of Ono's status as a widower, but it also presents clues to how he as a narrator will tell his story. It establishes how unreliability works in the novel, and introduces Ono's preoccupations and tactics. Incidents that he mentions (or gives too little mention) will go on to be exposed as the essence of his current crisis. The novel instructs how to read it in these terms, with reputation immediately explicit as the narrator's focus. Ono's opening recollection is preoccupied with asserting the high status he held in the past, while also with false modesty claiming, "It may be that if I chose to put it to the test, I would again be surprised by the extent of my influence. As I say, I have never had a keen awareness of my own standing" (21). His speculation follows the opening scene of an "auction of prestige," in which Ono inherits the house of the famous Akira Sugimura when the family deems him most worthy by reputation to receive the 
property. Ono recalls "the deep satisfaction I felt when I learnt that the Sugimuras... had deemed me the most worthy of the house they so prized" (10).

However, these past triumphs are established as from a different world than today, as Ono realises, "these days, I hardly ever hear of the Sugimuras" (10). As Ono's narration moves back to the present, the meaning of the memory changes into proving just how much his world has changed. His narration progresses from the gratifying past to the post-war world, where Sugimura's old house, symbolic of both Ono's past reputation and pre-war Japan, remains in ruins years after the surrender. The next memory, of Sugimura's daughters coming to visit after the war, and Ono's dawning realisation that, "most of her family members from the time of the sale were now dead," sets up the past from the beginning of this novel as a realm of concealed tragedy (11). The depth of this sense of haunting but obscured grief is shown in the same scene when Ono becomes angry that Sugimura's daughter "made scant effort to hide the fact that her concern lay with how the house - rather than its inhabitants - had fared during the war; she gave only the briefest commiserations on hearing about my wife and about Kenji, before embarking on questions concerning the bomb damage" (11). The irony of this being the first allusion Ono himself has made to his wife and son's death does not explicitly occur to him. Although this information is given the scantest mention, (not only here but at all points in the novel) it is at the ground zero of Ono's crisis of masculinity: his feeling of failure as a patriarch.

This new knowledge of Ono's own tragedy, although exposed subtly, throws his interactions with Sugimura's daughter into a new light. Its importance to the whole narrative and all other events and modes of narration is only revealed gradually. After recalling his own grief, Ono begins "to notice how her eyes would roam involuntarily around the room... and I realised she was experiencing waves of emotion at finding herself back in this house once more" (11). But he has revealed already how this house holds as many painful associations for him as it does for Sugimura's daughter. These emotions occur not only in her, but in Ono himself once we refuse to let him obscure the tragedy revealed a few sentences earlier. This is the first of many times in the novel when Ono will inadvertently reveal a personal tragedy which he is unable to make the explicit focus of his narration, but which nevertheless changes the meaning of everything once revealed. In the context of the rest of the novel, this interaction with Sugimura's daughter can be read as a minor instance of what Ishiguro has called "appropriation," in which Ono sees or projects his own negative associations with the house onto his guest (Holmes 18). Through narration her emotions cease to be entirely her own, as Ono finds further meaning in connecting them to his 
experience. He is in some way able to share his grief with this cold woman because of the way his crisis projects itself everywhere.

Proceeding through the novel, many of the themes, tactics, and points of crisis are established in the concealed workings of this opening memory. It sets the precedent for how the psychological dynamics involved in Ono's memory are inseparable from his recounting of events. Most obviously, it reveals the way in which Ono finds the world has moved past him, and how he is eager to move his focus back to a time when concrete, provable examples of his reputation and influence were apparent. It also acts as the first demonstration of his crisis: Ono exposes his anxiety over the point of reputation by returning to it again and again, lingering over memories which prove his influence in the past. Ono has found in his old age that the ideas of masculinity to which he has devoted his life to no longer yield the gains he thought they would, and that they have in fact cost him the lives of his family - at least in his mind.

This defensive use of memory is established as a pattern in Ono's narration soon afterwards, when his older daughter, Setsuko, approaches the question of why her sister Noriko's earlier marriage negotiations fell through. She does so in a roundabout way typical of her, and Ono replies "a little coldly, 'it remains equally a mystery to me. If I knew, I wouldn't keep it a mystery from you" (18). This cold reply is a reaction to what Setsuko is suggesting (or at least what Ono reads into her repeated questions): that Ono's ruined reputation caused the abrupt end of the marriage proceedings. Responding to this, Ono follows the conversation with a compulsively placed memory from before the War. $\mathrm{He}$ abruptly recalls how his former student Shintaro once came to express his indebtedness to his teacher for help in beginning his career. Using this memory, Ono creates an incredible line of logic in which it is in fact his high esteem which caused Noriko's marriage arrangements to break off: "My feeling is that it was simply a matter of family status. The Miyakes, from what I saw of them, were just the proud, honest sort who would feel uncomfortable at the thought of their son marrying above his station" (19). Ono doubles down on this complete reversal of what he has neurotically read into Setsuko's questions, naively communicating his obsession with the question of reputation by once again repeating how in the marriage arrangements "I was very lax considering the matter of status, it simply not being my instinct to concern myself with such things. Indeed, I have never at any point in my life been very aware of my own social standing, and even now I am often surprised afresh when some event, or something someone may say, reminds me of the rather high esteem in which I am held" (19). The juxtaposition between scene and commentary signals Ono's unreliability to 
the reader. Ono exhibits an obvious anxiety about his reputation, while at the same time insisting that he is unconcerned. This contrast, to which Ono seems oblivious, exposes him more clearly as using memory to present himself in a certain way. Memory is introduced as an instrument of Ono's crisis of masculinity. He is clumsy in his deployment of it here, but memory is nevertheless established as a mechanism that can be used to reconfigure the meaning of other scenes. So, when Ono detects the suggestion that he is implicated in his daughter being unmarried, he once again feels the full weight of his crisis related to his failure of patriarchal duties, and tries to spin things another way.

This understanding of memory as tactic introduces the broader role of unreliability in the novel. The unreliability of Ono's narration is structured by his effort to protect himself from personal tragedy. For the most part he is not actively misleading about his past, but allows assumptions the audience might make to go unchallenged. The roundabout way he approaches his memories is clearly bracketing off sections of his past and his character which are too inconvenient or painful to return to. The psychological structure of the narrative conveys this "bracketing", as it moves ever so gradually, reluctantly, towards the central memory of Ono turning his pupil Kuroda over to the police. But the key example among these preclusions is that he omits his most painful memory from narration entirely: the death of his wife. His failure to protect his wife - in fact, his affiliation with the system which caused the death of his wife (the imperialist militarism which led to World War II) - is simply impossible for Ono to confront directly. Ono does everything to avoid this truth, but it is precisely in his avoidance that he exposes himself. This has already been demonstrated with how Ono exposes his obsession with reputation through his overemphasis on his disregard for it. The structure of unreliability discloses the psychological dynamics of the crisis of masculinity, while at the same time acting as the manifestation of the crisis of masculinity. ${ }^{12}$ By coming into being in the form of unreliable narration, the crisis of masculinity makes itself detectable and its carrier suspect. By avoiding mentioning the grief he feels about his wife's death during the war, Ono finds an alternate way of communicating

\footnotetext{
${ }^{12}$ Masculine crises drawing attention to themselves through their attempt at concealment (unreliability) is an act of what Elizabeth Cowie, Jennifer Friedlander and others have called (drawing on Lacan) "masculine imposture" (Friedlander 64). Man may demonstrate all the trappings of authority and hierarchy, but according to Cowie this fools no one, as "what is signified in a making present of something is in fact a statement of what is absent" (Cowie 245). Friedlander makes the comparison to a toupée: "The response of wearing a toupée follows the logic of imposture; it functions as an attempt to hide 'the flaw,' but if its presence becomes apparent, it works instead to draw attention to what is absent. In that respect, then, rather than mask one's lack of hair, a toupée functions as a signifier of that very lack" (64). As unreliability becomes apparent to the reader, it functions precisely to draw attention both to its status as masculine imposture and the masculine crisis which prompted it.
} 
the force of his sadness. The very act of avoidance becomes the crucial storytelling device for crisis and the tragedies which induce it. ${ }^{13}$

The narrative contains several clues to the extent to which Ono might be aware of this alternate line of communication. A comparison can be drawn between this paradoxical unreliable narration which performs crisis while disclosing it, and Ono's commentary on painting self-portraits: "I cannot recall any colleague who could paint a self-portrait with absolute honesty; however accurately one may fill in the surface details of one's mirror reflection, the personality represented rarely comes near the truth as others would see it" (67). Ono's subtle imperative to his audience seems to be to read the novel as a self-portrait. Within narration itself Ono is identifying the inevitability of unreliable narration. Here as well, he articulates Lacan's distinction between the seeing and seen self, and glimpses the artist's role of navigating these two identities - the impossibility of expressing the jumble of one's inner world, thoughts and good intentions in a way that will ever satisfy others. As his explanation on self-portraiture shows, part of this project seems to involve an interrogation of not only how he has failed in the past (how he was complicit in stirring the appetite for war), but also how he is continuing that failure through unreliably representing his past.

Thus, Ono is forced to approach his most painful and guilty memories due to his crisis of masculinity, while also examining the process through which he does this. That phrasing, "the truth as others would see it," is crucial because through unreliability the narrative only presents competing truth claims. It never outright denies Ono's version of events, only suggests that it is unique to him. The following close readings examine how Ono's version of events is challenged, while no other character offers a purely reliable version of events to privilege instead. This diegetic world itself is shown to perhaps engender unreliability. The historical setting of the novel, as well as Ono's crisis-ridden perspective, mean that every character seems in some way consumed by a crisis of their own.

\footnotetext{
${ }^{13}$ Slavoj Žižek tells a joke which illustrates the significance of this absence: a Moscow art exhibit displayed a painting, entitled Lenin in Warsaw, that shows Lenin's wife in bed with "A young member of the Komsomol." A visitor is confused, and asks their guide, "[B]ut where is Lenin?" The guide "quietly and with dignity, replied 'Lenin is in Warsaw"' (Žižek 159). The visitor makes their mistake because they assume that what the painting represents (Lenin's wife and her partner in bed) must be what the painting is about. Really, the title embodies what is missing from the picture. And so, the painting becomes the materialisation of Lenin's absence, just as An Artist of the Floating World becomes an explanation of what Ono does not include: memories with his wife.
} 


\section{The Cultural Crisis}

From observing these crises in other characters, it appears Ono's world has changed not just from his perspective, but on a broader cultural level. Ono longs for a past familiar world with the old cultural touchstones and shared identity. As is established in the opening scene, the cultural past is a refuge for Ono from his current divided self and diminished reputation (at least at the beginning of the novel). As Ono navigates the differences between his past and present, the entire storyworld is represented as engaged in a similar crisis of adaptation to the new order. Again the opening scene of the novel sets a precedent: Ono's grief is shared with Sugimura's daughter, and through the novel with practically every character making sense of their lives in post-war Japan. In some ways Ono's crisis seems unique: his guilty conscience is so crushing because he is uniquely to blame. But, in another way, he finds his story replicated across the whole culture, as everyone steps into a new era where the rules are uncertain.

Through the first part of the novel the character of Shintaro is Ono's touchstone to the past. Ono openly describes how,

There is something reassuring going into Mrs Kawakami's and finding Shintaro sitting up there at the bar, just as one may have found him on any evening for the past seventeen or so years... it is really as though nothing has changed for Shintaro... he will continue to address me as 'Sensei' and maintain his most respectful manner towards me. (22)

Shintaro in fact becomes a vehicle through which Ono expresses his hostility to the new world, claiming "One should be thankful there are still those uncontaminated by the current cynicism. In fact, it is probably this very quality of Shintaro's - this sense that he has remained somehow unscathed by things - which has led me to enjoy his company more and more over these recent years" (23). As the reinvention of Japan ramps up, what Shintaro represents to Ono becomes more valuable. Ono is desperate for the certainty of status and power that Shintaro's treatment of him grants, but the reality of the rest of the world leaving this image of him behind makes this continued fantasy between teacher and student impossible to maintain.

We therefore understand Japan from the opening of the novel as in a state of reinventing itself with Ono out of step with the new order. Ono does not respond negatively to the present simply out of reaction, but sees it instead as the world he has created through his series of failures as patriarch in the past. He structures his life story in the novel as 
creating his present. This is the essence of his crisis, and makes it one centred on giving his life a kind of narrativity — an explanation for his failing to protect his family as a father and husband ought to. Therefore, Ono approaches this national reinvention as though it were a kind of theme, and represents people as symbols to evoke memory and characterise the new and old worlds. In Ono's narration this reinventing is not something happening simply on a broad cultural or societal level, but a process which has infiltrated each individual's presentation of themselves. In this world of crisis it is not just Ono who feels the great shadow of personal and political history colouring his life and self-perception, but his narration instead presents a whole country as being haunted and consequently rewriting itself right down to the level of individual pasts. ${ }^{14}$ The most brutal evidence of this is the multiple reports of famous figures committing hara-kiri, ritual suicide. Those unable to be reconciled to this new reality, those who remain overcome by crisis, must kill themselves. The threat that looms right through to the end of the novel is whether Ono will feel this action necessary for himself.

In this context of reinvention Shintaro again becomes an emblematic figure. He remains the ingratiating, deferring character we have known right up until halfway through the novel, at the beginning of part two. At this point his role changes, and instead of offering a sanctuary from Ono's crisis, he brings home its inescapability. Shintaro is seeking a position as an art teacher at a college, and Ono finds him at his doorstep once more. In Ono's memory this scene is presented as an almost perfect rhyme with the scene from the beginning of the book mentioned earlier, when Shintaro came to Ono's house to humble himself before his Sensei in gratitude. In Ono's artist's mind the scenes are rewritten as bookending one another, and as taking up a whole cultural significance for how the world has changed after the war. Both begin with Shintaro prostrating himself in traditional fashion before the entranceway to his master's home, saying in the first scene: "No, Sensei, it is the height of impertinence. Really," and in the second "Sensei, it is a great impertinence of me to come here like this" $(20,100)$. Ono confesses that he "felt something akin to relief, as though things were returning to a more familiar footing" when he finds Shintaro outside his house (100). The scene goes on to be the complete inverse of that from the book's beginning. Rather than to express gratitude for the help Ono has provided to him and his family,

\footnotetext{
${ }^{14}$ For Timothy Wright the novel is not really focussed on Ono at all, "but rather the working of history itself" (63). His analysis shows how “Ono's personal self-deceptions and concealments point to much larger forms of self-deception and concealment at the level of the nation" and demonstrates the point of what I have called cultural crisis when explaining how, "The guilt, in other words, is not purely Ono's" (63).
} 
Shintaro now comes to his former teacher to request a letter of disassociation. He tells Ono, "I would be most grateful if you would yourself write to the committee, just to confirm certain statements I have made... You may recall, Sensei, how we once had cause to disagree. Over the matter of my work during the China crisis"' (102). Ono recalls no such disagreement, but after some back and forth he catches on to the true nature of this visit and responds, “'You wish me to write a letter to your committee,' I said eventually, 'disassociating you from my influence. This is what your request amounts to"' (103).

It comes as little surprise that Ono is able to pick up on the truth behind Shintaro's visit, as in fact for the first half of the novel his own actions and narration have been driven by the same desire to conceal, dissociate, and rewrite. This is the irony behind his advice to Shintaro: "Why don't you simply face up to the past?" (103). For the first 100 pages Ono has been the figure obscuring the past, not giving the audience a clear understanding of why his paintings have been "tidied away," or why families become suddenly reluctant to be joined with his through marriage (32). His readiness to express in narration that this results from his activities in the lead up to World War II has developed gradually, but Ono is still yet to fully confront his crisis. The contrast of the two scenes shows not only how Ono's reputation has fallen, but also how the reasons for his crisis and unreliability in fact consume every character. All Japan, according to Ono's narration, is in a process of reimagining its past. Shintaro's switch at this point from symbol of nostalgia to symptom of reinvention shows how this whole world is motivated by principles of rewriting - an entire setting made unreliable as norms rapidly change.

Through the early scenes in the book, Ono's experience of being alienated from the new Japan is presented as a result of his particular crisis over complicity in the crimes of the war, and the terrible personal toll this implicates him in. Ono remains notably more implicated in this history than other characters, but in his interactions with others we begin to read memory as tactic everywhere. There is almost an understanding in the dialogue that everyone is after self-preservation — everyone has a guilty past. ${ }^{15}$ Here Bakhtin's claim that, "within the arena of almost every utterance an intense interaction and struggle between one's

\footnotetext{
${ }^{15}$ A fascinating study by Motoyuki Shibata and Motoko Sugano explores how the initial Japanese translation of the novel attempted to suppress this unreliable element in the storyworld present. Shibata and Sugano explain: "Rather than translating... militarist slogans and songs by using the same writing system as the contemporary narrative, [the translator] reverts to an archaic form that creates a jar in the translation, reinforcing the discontinuity between Ono's own language and consciousness of the past and present. The effect gives emphasis to the fact that he used to utilise the language of the imperial government but that he now no longer uses that discourse. The distinction also makes it seem as if the politically sensitive problems of the past are resolved" (31).
} 
own and another's word is being waged" rings very true, as we observe the struggle over meaning between teacher and pupil (Dialogic Imagination 355). So, when Ono claims he cannot remember Shintaro voicing any objections at the time to the "China crisis posters," his old student grows desperate, and it becomes unclear whether he is asking Ono to in fact "remember" something that really happened, or is asking him to rewrite history to place his student in a more advantageous place: "'I beg you, Sensei, to try and recall that little disagreement. Grateful as I was - and still remain - for the wealth of things I learnt under your supervision, I did not always, in fact, concur with your view" (103). If he is only asking Ono to recall an argument, why does he contrast their statuses in the following way: "It is all very well to reflect and ponder when one is in retirement. But as it happens, I live in a busy world and there are one or two things I must see to if I am to secure this post... Sensei, I beg you, please consider my position" (104)? Shintaro's plea to Ono reveals a lot about the nature of memory in this world, setting it up as something which is worked on, which emerges as a result of consideration and towards a specific end. The structure of the novel leads the reader to ask whether these two artists are in fact arguing over what narrative version of the past will prevail. Ono suggests his crisis may be reflective of something happening more broadly across a culture. Because so many are complicit in a guilty history, a new kind of complicity is developed within the narrative, where characters are working together to reinvent themselves and their world. Perhaps because he is simply too implicated in the wrongdoings of the past, or because his guilt and crisis overwhelm him, Ono is unable to fully participate in this new project, and resists Shintaro's plea. Nevertheless, Ono's construction of this setting establishes the novel's sense of unreliability as focussed on that which is withheld, and in doing so adds to the understanding of this as a whole world of unreliability. ${ }^{16}$

However, the difficulty of interpreting such scenes becomes clearer the more the inescapability of Ono's vision is shown. We begin to register how the conversations are less reflections on the state of the world as on the state of Ono. He sees, and tells the narratee, what he feels. In doing so, he sees versions of his own guilt in everyone. In one reading of Ono's unreliability, all characters seem to be aware of a much wider dialogue than themselves, where everything they say can be somehow implicating. But in another reading, Ono's preoccupations are simply projected onto everyone else, and the reader is carried along

\footnotetext{
${ }^{16}$ Barry Lewis even suggests that the novel is a kind of sociology of Japan, and that, "Ishiguro's Japan is not a country but a system, a system which he calls: Japan" (26).
} 
in his vision. Ono's psychology is recognised as occluding parts of his past — so can the language of his narration, in Bakhtin's sense, be trusted in his readings of others?

For instance, we know Ono to be unreliable, and yet we assume his reading of Shintaro's request - that it represents his inability to "face up to the past" - is the truth. Ono himself does not even expressly deny Shintaro's claims to have "expressed misgivings" about the school's direction, instead only claiming that he does not "recall what it is [he is] referring to" (102). But Ono has positioned the reader into a suspicious cast of mind. In Ono's narration, the idea of the past being rewritten and concealed is gradually made natural and expected. The irony in this scene, therefore, is that Ono makes his own implication (that Shintaro is lying about the past) believable precisely because he has exposed why his narration ought to be subject to suspicion. He has made us suspect others because of the way he himself is suspect. This event becomes one of many through these three novels in which the unreliability of a narrator is revealed, but there is nothing to replace his version of events. Ono is a reliable register of unreliability, but gives no alternative version to retreat to, being unreliable himself. The crisis of masculinity in this sense portrays the world as only a collection of competing truth claims, denying a consensus reality, only capable of comprehending the world as individuated languages.

Ono's role of interpreter of others' lives places him on the edge of subjectivity and objectivity, a place the novel posits as at the heart of the artist's role. The whole timeline of memories in the novel is about his growth into an independent artist. But one memory from his childhood stands out as suggesting the origin of the artist's instincts that he displays in narration. This memory involves the culturally important reception room. Ono is explaining the respect he still holds for the reception room of any home, remembering how his father instilled this in him by forbidding Ono from entering or seeing the room until the age of twelve. He explains,

That room being in many senses the centre of the house, curiosity compelled me to construct an image of its interior from the occasional glimpses I managed to catch of it. Later in my life I was often to surprise colleagues with my ability to realise a scene on canvas based only on the briefest of passing glances; it is possible I have my father to thank for this skill, and the inadvertent training he gave my artist's eye during these formative years. (41)

This training of Ono's "artist's eye" is an important detail not only for his memory of past scenes, but for his ability to fill in the gaps. He has a talent for assigning meaning where there are holes - he is able to fill others with his own sense of guilt or grief. By the time that Ono 
takes up his narrator functions, this imaginary capacity is channelled in the service of his crisis of masculinity. Once again, Ono explains his method as narrator within narration itself. The passage's account of how Ono moves a real-world response into an artistic technique prompts the reader to consider the ways his narration makes use of these same techniques. Consequently, we understand Ono as a storyteller, and his narration as another artwork. In the memory of Ono from childhood, in other words, there can be found both an example of his unreliability as well as an explanation of how and why he is unreliable.

In this way Ono's narration continually provides us not only with the means of detecting unreliability, but also with a history of his unreliability in a way that makes his narration about itself_ —or, more precisely, about the process of storytelling. By projecting his unreliability onto everyone else, and seeing his crisis of masculinity everywhere, the focus shifts from what Ono is unreliable about to how and why he is unreliable. When crisis is understood as the psychological process behind this, the novel becomes about the way crisis makes every level of the narrative about itself and about the obsession with it. In Ono's representation, art and the crisis of masculinity develop a strange relationship in which crisis acts as a kind of (destructive) creative drive.

\section{Art as the Space of Crisis}

It is in this context of Ono's "artist's eye" that his crisis turns his narration into much more of a project, and something through which he can bring his artistic capabilities to bear. Furthermore, through the societal or cultural view of this, the reader is signalled to locate this storytelling not just in Ono's awareness of structure or theme, but in character itself. Through Ono's memories the novel presents a whirl of characters: Sasaki, Mori-san, Ono's father, the Miyakes, the Saitos, Suichi, Kuroda, Kenji, Ono's wife, Matsuda, Shintaro, the Tortoise. The blurring between all these names and faces is significant. What is important about this flurry of small memories and actors is precisely that all these names become to an extent indistinguishable from one another. There are more central characters, such as Kuroda or Matsuda, but overall the reader is made to experience these characters as coming and going from Ono's memories easily, but also representing general "types" for him. In Mori-san and his father he finds the authority figure to rebel against, in Shintaro and the Tortoise the admiring student. It is no surprise that Ono confuses the memories of characters, as he engages with them in memory for their archetypal significance, rather than as individuals. 
This gives the novel "the texture of memory" which Ishiguro seeks, but also builds towards something greater at the heart of the novel. Consider Ishiguro's definition of how we "appropriate": "Our view of other people is often shaped by our need to work certain things out about ourselves. We tend to appropriate other people - more than we perhaps care to admit. We perhaps don't see them for what they are; they become useful tools" (qtd in Holmes 18). Etsuko uses Sachiko and her daughter in this way in A Pale View of Hills, but in his second novel Ishiguro amplifies his use of this technique to correspond to Ono's crisis of masculinity. Ono does not engage with characters as they are, but he returns to them in memory in terms of how they correspond to his present crisis, and always as an explanation of it. ${ }^{17}$

Sifting through Ono's crowded recollections, only two memories truly matter on their own terms, and are the mainsprings of Ono's crisis. Of these, only one is actually narrated: his betrayal of Kuroda. The other memory, the raid in which his wife died, is only hinted at. Both strike precisely at the guilty origins of his crisis: his failure in duty as a patriarch. When he meets Matsuda at the end of the novel he is told: "It's just that in the end we turned out to be ordinary men. Ordinary men with no special gifts of insight. It was simply our misfortune to have been ordinary men during such times" (200). But Ono's misfortune runs much deeper and more intractable. For he has not thrown his life away, but has thrown away the lives of others - the lives of the people he loves most. Matsuda does not mention that the consequences of Ono's being an ordinary man mean that he is complicit in the death of his wife and son. Everything in the novel, especially the depiction of other people, is about this. Ono's unreliability seems to stem from a falling reputation in a narrative world which prizes reputation as of the utmost importance. But what the damage to his reputation actually means to him is a much more personal and tragic loss that comes from his inability to protect his wife and son.

In approaching this understanding, Ono moves through his life in a kind of therapeutic way. It is only through previous memories that he is able to access deeper ones. Thus, in order to tell the memory of turning Kuroda over to the police, he must tell the story of his leaving Mori-san's teaching; in order to tell this memory, he has to remember how Sasaki left

\footnotetext{
${ }^{17}$ As a result of this appropriation, Margaret Scanlan makes the point that, in the novel "the personal identity with which first person narrative is usually identified is far from solid... when he [Ono] talks about other people, he frequently appears to be talking about himself... a familiar psychological defence, but in Ono's case, it seems to point to a more fundamental confusion of himself with the people he discusses" (145). Through her analysis of appropriation Scanlan argues that Ono's identity is "de-centred" (145). I make the opposite case: that through appropriation Ono's identity begins to envelop everything, while also allowing for the communal/empathetic potential (a process Ishiguro deepens in the following novels).
} 
Mori-san as well, going all the way back to how he disappointed his parents in childhood. The poetry here, in which each memory builds in significance, corresponds not just with the reader's growing understanding of Ono's crisis, but with the story he has to tell himself in order to arrive at what his true preoccupations are. There is a self-conscious structure to be found within the synthetic narrative structure-within Ono's own psychological process. Therefore, the way memory works in the novel is Ono's searching through his life and assigning a newly discovered significance to events which he thought little of at the time. This is the way Ono makes his own life a work of art: his discovery or invention that there is a deeper meaning to events which he uses his "artist's eye" to spot in retrospect.

In Ono Ishiguro finds new empathetic power in his concept of appropriation. Ono, like everyone, is making sense of a world that has been devastated by war. In one way, Ono's awareness is left so impaired by the personal toll of the war on him that he cannot see beyond his specific tragedy. But in another sense, his tragedy allows him to accurately perceive, and feel on a deeper level, the pain and crisis which the war has left in everyone. Refering back once again to the representative opening memory, would Ono as an artist be able to truly represent the painful memories Sugimura's daughter is experiencing were it not for his own parallel experience? Ono's artist's eye places him in the role of filling in the gaps of others' suffering. He feels and sees the aftermath of war in a way that resonates directly to his personal experience.

Because of this, the realm where Ono's crisis of masculinity is most obvious is consistently other characters. Returning to this idea of a whirl of characters, difficult to differentiate and cropping up in increasingly similar memories, it becomes clear that Ono, in his memory, does not see these figures as they are, but engages with them only as figments of his crisis. They set things up so that his current course seems inevitable. One tactic of Ono's narration is the way he blurs his own speech with those of others. This is particularly the case with his teacher Mori-san, as the lines between his own actions and those of his teacher become less clear. After all, Ono too has occupied the role of teacher. It is also Ono himself who questions his recollection of this dialogue, asking himself multiple times how that can truly be what Mori-san said, when it is a phrase he himself so often uses. He catches himself in the act of appropriation: "It is possible, of course, that Mori-san did not use those exact words. Indeed, on reflection such phrases sound rather more like the sort of thing I myself would declare to my own pupils" (151). These small slips build in significance, like everything in the narrative, until the final scene with Mori-san in which the blurring of Ono 
as teacher and pupil means he remembers two different events almost at once. This finale includes another example of Ono confusing his own dialogue and Mori-san's:

Of course, he may well not have used that precise phrase, 'exploring curious avenues'. For it occurs to me that expression was one I myself tended to use frequently in later years and it may well be that I am remembering my own words to Kuroda on that later occasion in that same pavilion. But then again, I believe Mori-san did at times refer to 'exploring avenues'; in fact, this is probably another example of my inheriting a characteristic from my former teacher. (177)

Though he tries to present them as such, mistakes like these are not just a blip in Ono's memory. In this moment Ono recognises two strains of his unreliable memory. Firstly, he confesses his act of appropriation and blurring, the way he has consumed parts of his memory of Mori-san into himself. Other characters exhibit the crisis of masculinity in the same way Ono does because they in some way are Ono. Secondly, Ono anticipates the ambiguity within the vital memories to follow, in which the stories of Kuroda and Mori-san are collapsed into Ono's, as he becomes a blend of master and pupil.

This compositing is the climactic scene of the novel, in which Ono almost has a confrontation with himself at two different stages in life. Ono has transgressed the traditions of his painting school and has been shunned by his fellow students. His paintings in his new style have been taken, and Ono here asks his teacher about their whereabouts. Mori-san has taken them, and says,

"I was told there were one or two other paintings you've completed recently that were not with those I have now."

"Quite possibly, there are one or two I did not store with the others."

"Ah. And no doubt these are the very paintings you are most fond of." (178) This final line of dialogue rings out as an almost exact repetition of a line spoken by Ono's father during the earlier memory of him burning his childhood paintings: "And no doubt, Masuji, the missing paintings are the very ones you're most proud of. Isn't that so?" (43). It is a moment not unlike the ending of $A$ Pale View of Hills, in which the permeability of reality suddenly strikes, and the reader and narrator seem to acknowledge together how narrativity has altered reality. Ono's case is more ambiguous even than Etsuko's in the previous novel, as it is impossible to know which memory is distorted, or if either are. This is impossible not just for the reader, but for Ono himself. These two authority figures, whose teachings Ono will eventually outgrow, form an almost perfect rhyme in his memory. But the memories are not just confused by how the figures of Ono's father and Mori-san bleed into one another, but 
also in the way the events themselves become linked in the biography of Ono's crisis. In connecting them through dialogue the way he does, Ono sets out even more clearly the causal chain as he sees it - a causal chain which, like all things in his memory, will lead to his wife dying and his current guilt. Crisis in the book makes all prior events reorient themselves towards it, so that Ono's revisiting of both his business meetings with his father, and his final meeting with his painting teacher take on a new resonance for him which sets him on the path towards his current situation.

This connection is spelled out further by moving seamlessly from the memory in which he is the student being betrayed, on to the memory in which he is the teacher and the betrayer. This is of course the scene which has been alluded to since early in the novel, the scene which Ono cannot get off his mind: his betrayal of Kuroda to the police. He briefly introduces the memory with preamble that seems to be about Mori-san, only afterwards revealed as being about himself: "when a master painter has given so much time and resources to a certain pupil... it is perhaps understandable if not entirely excusable, that the teacher lose for a moment his sense of proportion and react in ways he may later regret" (181). He goes on to expose what he is really talking about by instantly moving from one memory to another: "For all that, it is clear that such arrogance and possessiveness on the part of a teacher - however renowned he may be - is to be regretted. From time to time, I still turn over in my mind that cold winter's morning..." (181). Ono continues onto the memory of his discovery of Kuroda's arrest, his guilt over which has been exposed already through the way his student's name has cropped up again and again through the narrative. Unbelievably, we learn too that "it was in that same pavilion [that Mori-san tries to get Ono's paintings], just before the start of the war, that I was to have my last conversation with Kuroda, the most gifted of my pupils" (175). The similarities here strain credulity. In what we read as a piece of realist fiction this simply seems too unlikely - once again too many perfect rhymes. A kind of collapse of a whole series of different events seems to have occurred. Just as Ono admits to possibly "inheriting" a turn of phrase from his teacher, has he in some way inherited his memories, projected himself into that role of "possessive teacher?" Has he simply conflated the two memories because he sees himself, and more importantly his crisis, in everyone? It is impossible to ascertain whether both similar scenes occurred as he describes in Ono's cyclic view of history. We cannot know the true events behind these memories, but one thing does become obvious: to Ono the one explains the other, as well as explaining his own mixed sense of being wronged, and his enduring shame over his betrayal of his student. Ono 
intervenes and rewrites the narrative of his life in a different, more active sense here. He is not explaining what happened in his life; he is explaining why his crisis exists.

There is then a simultaneous unreliability and deeper reliability provided by memory and crisis. On the one hand, Ono becomes unsure where words and phrases came from, which person and memory to attribute them to. On the other, his memory in the context of unreliability allows him to make an evaluation of the importance of these scenes - the truer importance in the context of the most significant occurrence in his life: the death of his wife and his resulting crisis. Crisis operates here in connection to an anamnesis, or "unforgetting," in which Ono's awareness of his failure to protect in the present allows him to discover a meaning in his prior actions which had been hidden. To Ono as narrator, his life only makes sense in the context of the crisis of masculinity building inevitably up towards the defining event - the deaths of his wife and son. In his acts of appropriation Ono is not placing his personal tragedy as uniquely important, but navigating the objective and subjective worlds so that he constructs a representative narrative for a society in recovery from tragedy and crisis. With this recognition, the imperative to the reader is to forget the search for the illusion in the reality, and instead to find the reality in the illusion. His unreliability means something for everybody.

This rewriting of Ono's life designates his crisis as an event which changes not only his present or future, but his past as well. This is the way anamnesis works within crisiscrisis becomes such a totalising force that it appears as though it was what the narrator was working towards his whole life without realising. What we understand in this conception of crisis is an extension of the same logic behind Ishiguro's interest in appropriation: the permeability of reality. Ono's story presents the ways this might be true of time as well as character, and acts as an antecedent to an idea that becomes more central in The Unconsoled.

It is in this sense that Matsuda and Setsuko miss the point when they try to put Ono's career in perspective for him. Ono's approach is the same as Ishiguro's in finding importance not in the wider political and cultural effects, but in the internal experience of these things such as time. In their final conversation of the book, Setsuko tells her father:

Forgive me, but it is perhaps important to see things in a proper perspective. Father painted some splendid pictures, and was no doubt most influential amongst other such painters. But Father's work had hardly to do with these larger matters of which we are speaking. Father was simply a painter. He must stop believing he has done some great wrong. (193) 
What Setsuko misses is that Ono's sense of responsibility is not ordered along the logic of historical events and their cause and effect, but rather on the feeling of his failure as patriarch and how the contradictory demands of masculinity have overwhelmed him.

Instead of time or logical outcomes, the series of events imagined to lead to Ono's crisis is communicated symbolically_via smoke. Ono the artist, with the awareness of a fictionality or artistry to his narration, draws on a symbolic device to give the biography of his crisis coherence and subtly communicate significance. The references to smoke and fire appear in such a way as to make their true significance imperceptible until the final pages of the book. However, the allusions begin from very early on, only becoming noticeable once Ono is ready to reveal his most significant memories. One of the most significant evocations of the symbol comes near the beginning of the book, where it can be easily overlooked. Here, Ono reveals much about the symbol's metaphorical meaning to him:

One evening not so long ago, I was standing on that little wooden bridge and saw away in the distance two columns of smoke rising from the rubble. Perhaps it was government workers continuing some interminably slow programme; or perhaps children indulging in some delinquent game. But the sight of the columns against the sky put me in a melancholy mood. They were like pyres at some abandoned funeral.

Ono in this moment is honest about his feelings in response to the smoke, but withholds the cause in his own life for that response. The limits of his honesty are only fully revealed in the final conversation of the novel, with Matsuda. It is in that conversation that his wife is at last mentioned again with real emotional engagement. Here, Ono says, "The smell of burning still makes me uneasy... It's not so long ago it meant bombings and fire," and then finally he says, as though it were the natural corollary to this: "Next month, it will be five years already since Michiko died" (200). In the connection he draws here between burning and his wife's death, he evokes dialogue about his wife from his other meeting with Matsuda at the end of the book's first part:

"A cruel thing," Matsuda said, sighing. "And with the war all but over. I heard it was something of a freak raid."

"Indeed. Hardly anyone else was hurt. It was as you say, a cruel thing." (90-1)

Therefore it is only at the end of the novel that symbolism employed throughout the text falls into place. The movement of the novel is a ramping up of symbols in this way, with the gravity of each growing exponentially. At the time of the first mention of smoke it can be regarded as Ono regretting the damage to the city, while at the final mention the depth and 
insolvability of Ono's tragedy is fully uncovered in a way that throws all prior memories into a slightly different light.

There are three painful memories which Ono recounts connected to smoke: The first is the memory from his childhood when he tries to hide his favourite paintings from his father. In this scene, Ono remembers himself smelling burning, his assumption being that his father is burning his early paintings. Is it this earliest memory of smoke which causes the future associations with trauma? Or does he project the smell of smoke backwards on to his past? The possibility also exists that this painful pattern is a real synchronicity in Ono's life, a series of coincidences which mean that some of the hardest moments of Ono's life do not appear discrete, but within a chain of gathering meaning. Thus, this original memory of smoke seems to in some way anticipate the later events, (certainly the later burnings of paintings), all the way up to the final, unspoken memory of the American raid. Which of these is true-figment of imagination or real coincidence-is impossible to say. All the reader has access to is Ono's experience, and for him burning still appears to hold real, dark meaning.

As analysed earlier, the truth of Ono's childhood memory is complicated by its similarities to his final interaction with his teacher Mori-san. This is his second memory of burning. Here burning initially has no negative association, Mori-san simply says, "Ono, there are some matches and tapers in our kerchief. Kindly light these lanterns" (176). Ono earlier in the novel remembers how, if the leading student "Sasaki were to suggest a person's painting was in any way 'disloyal' to our teacher, this would almost always lead to immediate capitulation on the part of the offender - who would then abandon the painting, or in some cases, burn it along with the refuse" (140). And with Ono's traumatised associations in mind, the reader can feel his approaching realisation that his sensei has burned his paintings as he asks for them back and is told, "No need to bother with those paintings, Ono. It will be sufficient if you find the remaining ones and bring them to me" (179).

The third and final memory of burning Ono addresses directly is his arrival at Kuroda's home, and the sight of his paintings burning. In this case we have other characters' dialogue to suggest the real centrality of smoke to the scene, as the soldiers say, "bad paintings make bad smoke" (184). Alongside this, there is Ono's continual return to the topic of Kuroda to suggest the way he is traumatised by his betrayal of him. This memory therefore contains burning as its more direct, verified focus, and evidence of the way this memory stays 
with Ono for its individual importance, not for its connection with other memories. ${ }^{18}$ The fog of crisis covers all three of these memories, and they prompt the question: what is the true origin of Ono's traumatised vision of burning? Which of the memories began this chain? Is there truly this pattern through the defining moments of Ono's life? Or is it rather that burning is connected to the site of his guilt and crisis, the war, and so just as he finds the origins of his crisis in earlier parts of his life, he finds the symbol of his crisis as well. Once again he appropriates his own memories, his own timeline, in the same way he appropriates other lives.

Ono's crisis of masculinity operates as a retroactive pattern-forming psychological process, and Ono's narration within the logic of crisis points to something through this pattern. All the memories are directed towards an absence in that they lead towards a final memory which remains untold. There is therefore a hidden fourth memory of smoke, too painful to recount directly. This we understand as the "freak raid" in which Ono's wife dies, and which he is thinking about constantly, without ever speaking of or narrating directly. Ono's crisis demands he in some way make sense of this tragedy, while simultaneously making him culpable for it in a way that makes it unbearable for him to address. In the brief description of Ono's son's funeral, he shows a glimpse of this aversion through his apparent complete lack of emotion. There is a harsh reading of this that Ono leads the reader into, which simply makes him a victim of his own propaganda, so hypnotised by his country's cause that he cannot realise what he has lost, and believes Kenji's death is worth it. What seems more plausible by the end of the novel, with the depth of Ono's tragedy revealed, is that here he is once again searching for a way to cope. When Suichi storms out of the funeral because he is "angry," and Ono dumbly asks, "Angry? What is it he's got to be angry about?" a deeper ethical dimension is possible (58). We must consider the way Ono is convincing himself that his son's death was a worthy sacrifice. This might not just be to absolve himself of responsibility, but to make his son's death mean something. The whole question of guilt or shame, and of Suichi's righteous anger, is complicated when Ono inadvertently reveals that he has lost as much as anyone. Once again, in this scene Ono is trying to bring a narrative to his son's death in a way which allows him to endure it.

In this view of Suichi's pain at the effects of the war, the truth of Ono's role is also made clearer. He is a storyteller not only of his own life, but for expressing a shared grief. His guilt is a societal guilt; what happened to his son happened to a whole nation's sons.

${ }^{18}$ Rebecca Walkowitz calls this the "primal scene" of the novel (128). 
Ono's unreliability facilitates his personal story to act as a myth in which crisis allows Ono to see his pain refracted across every encounter and individual, both in his present and backwards through his life. Ono's crisis of masculinity is exposed through its very means of assertion (unreliability), because he is constantly navigating this objective/subjective line, in which when he is talking about himself he is simultaneously talking about the generaltalking about history. ${ }^{19}$

The crisis of masculinity in An Artist of the Floating World is therefore a way of making sense of the unbearable parts of life. Ono's crisis of masculinity is caused by his failure to protect his family through the senseless violence in which he feels he played a part. His response, the way his crisis operates, is to make sense of things. In doing so, he makes sense of the feelings of a whole population recovering from war. Consequently, the massive importance of virtually everything Ono communicates becomes felt. Every conversation or setting is rewritten within the story of his crisis. The guilt Ono feels about his complicity is so intense that the focal points of his life become those moments which can be convincingly read as building towards his culpability. Thus, I identify crisis as a storytelling mode, and these narrators as storytellers. In Ono's case he does this not just for himself, but for those around him. Cynthia F. Wong makes a similar observation about how the selective narration of Ishiguro's early novels reveals significant aspects of each character's crisis, explaining how, "each narrator is in effect writing his or her own story along an emotional course to be tracked by a reader or listener who will bear witness to the tales" (18-9). Lacan's work seems especially relevant here, as the task of the artist-narrator is to reflect on the relationship between one's self-image and the image of oneself held by others. In this way, Ono carries his combination of pride and shame, and represents a grieving world through his individual unreliability. As Ono looks in the mirror, sees the way he is now thought of by the post-war world, his identity ceases to be a real life with different relationships and natural alterations, and becomes instead a consumable narrative, a themed work in which "people" become

\footnotetext{
${ }^{19}$ See Wright for more on the place of communal history in the novel. He sees Ono's historical position as archetypal for Ishiguro's narrators: "Ishiguro... chooses as narrators those maginalised from historical processes, those without agency, or without agency any longer. These characters' marginal relationship to history allows them to see history from a perspective not available to those in its main current" (86).
} 
"characters," and his wife's death becomes in some way explicable, if no less painful. In this light his narration is a part of a larger kind of gamesmanship between the affirmation and denial of identities, and demonstrates the crisis of masculinity as ultimately a force trying to reclaim some control through narrative power. The crisis of masculinity creates the drive to narrative coherence, and, to return to Alison Case's distinction rehearsed at the opening of this chapter, Ono's narration demonstrates masculinity's continued association with narrative control. 


\section{"The Professional Being": Expanding Narratorial Awareness and The Remains of the Day}

All sorrows can be borne if you put them into a story or tell a story about them.

-Karen Blixen

The character narrator of The Remains of the Day is not an artist, but he is a readerthough an abashed one. Stevens the butler reads "sentimental romances," a fact he attempts to conceal from his colleague Miss Kenton who asks him, echoing the readers' question throughout the early parts of the novel, "What on earth can it be you are so anxious to hide?" (175). Whether or not the arts are his strength, Stevens has a crisis which demands to be told, and The Remains of the Day follows An Artist of the Floating World in the pervasive sense that its narrator is, in a deep way, in control of the narrative. It is in fact precisely in details such as Stevens' defensive admission to reading, I will argue, that Ishiguro signals the authorial disposition and self-consciousness which lie behind this narrative of crisis. In these statuses he is not so different from Ono. Looking more directly at narrative theory here, Stevens' narration draws attention to the three elements of narrative and character identified by Phelan: mimetic, synthetic, and thematic. That is: the ways narrative creates the illusion of reality, the ways it stresses its nature as literary construct, and the ways it explores certain overarching ideas. These three elements are central to this chapter's argument as Stevens will appear to break the mimetic illusion of the novel in his narrator functions, and will act in ways which seem to depend on his synthetic status, all without truly violating mimesis. This is because, rather than being purely an artificial authorial device, unreliability is built into the storyworld of the novel through Stevens' crisis of masculinity.

The classic reading of Stevens is that he has been consumed by the lack of a language or ability to express his feelings. This is read as the situation which characterises Stevens throughout the novel with only a couple of lines as notable exceptions, and is often cited as the source of his unreliability. Phelan's analysis argues that Stevens' "misreporting [is] a consequence of his mistaken value system, which denies the importance of his own emotions" (Living 51). Ishiguro himself offers a reading along the same lines: "When Stevens says that [the greatness of Britain paradoxically comes from 'the lack of obvious drama or 
spectacle'] he is also saying something about himself. He thinks beauty and greatness lie in being able to be this kind of cold, frozen butler... And, of course, that viewpoint is the one that actually crumbles during the course of Stevens' journey" (Vorda 141-2). Both pieces of analysis are picking up on the use of unreliability as a way of foregrounding Stevens' psychology.

This chapter seeks to complicate this standard reading of Stevens' restraint by showing how Stevens' psychology—and the narrative it generates — are dictated by his crisis of masculinity. Although emotional muteness or repression are perhaps the most common feature of the popular understanding of masculinity, rarely is the crisis of masculinity behind Stevens' narration the focus of analysis for critics. ${ }^{20}$ This is understandable, given Stevens' own obsession with an alternative explanation for the denial of expression of his feelings what he calls dignity. In a novel in which the reader is trained to look for the gaps between the way Stevens defines himself and the way he acts, "dignity," however, becomes a central conceit used to reinforce one image of the self. Stevens" deployment of "dignity" is in fact a key operation demonstrating the pervasiveness of his crisis. ${ }^{21}$ Just as Ono and Ryder define their masculinities in terms of reputation and responsibility respectively, Stevens defines it through his harsh sense of duty, which he translates to himself as "dignity." Stevens" definition of dignity as never "removing one's clothing in public"-meaning always remaining in control of one's emotions and never giving way to sorrow, love, or sympathyis the source of his masculine discourse (Remains 221).

The crisis of masculinity has been described here as a process of one's principles becoming destructive in the effort to preserve themselves. It is therefore these terms (reputation, duty, responsibility) which are to become destructive towards the three narrators. Stevens has his whole professional life been "the prototype of an 'ideological servant': he never questions his role in the machinery, he never opposes his boss even when he makes obvious mistakes, that is, he does not think but obeys" (Salecl 180). As Stevens begins to

\footnotetext{
${ }^{20}$ As stated in the introduction, Linda Raphael is one exception here, with her work on "the play between masculine and feminine discourse" in the novel, and her overall persistent description of Stevens' as "masculine discourse" (Raphael 171). She identifies a gender dynamic in the novel which relies upon the juxtaposition of "mainly male myths [such as nation or history] with a nonmythical feminine discourse" (172). Alice Ferrebe is another critic who focuses on what she sees as Stevens' "masculine emotional repression," but unlike Raphael she argues that "the novel does not seek to uphold women as an antidote to masculine emotional repression or unreliable narration" (158). The diverging readings of just these two works points to an underexplored feminist dimension of the novel which merits further critical attention.

${ }^{21}$ Several critics have observed how Stevens is "unreliable in a very reliable way" (Shibata 52). He has various tics and signals, such as circling back to dignity and, as Kathleen Wall has suggested, grammatical switches which all consistently demonstrate moments of unreliability. I would argue that Stevens' consistency in these areas signifies an attempt to present a fixed image of himself and his associations with masculinity.
} 
recognise the incalculable cost his upholding the principle of duty has had on his life, he resorts to doubling down, outwardly appearing more invested than ever in the same old principles even as he further exposes and explores the ways they have betrayed him. Once again: masculinity becomes most dangerous when it is most fragile. It is this dynamic which characterises the storyworld psyche that lies behind Stevens' unreliability. He swings between professions of absolute commitment to dignity, England, and masculinity on to disclosures, which become more and more explicit, of his ultimate disinterest and sense of loss connected to these abstractions. This chapter will argue that Stevens' control over the narrative extends a degree farther than has been observed, and that his masculine crisis makes The Remains of the Day a novel just as much about his need to tell as his need to conceal.

What we begin to understand through a reading of Stevens as a narrator driven by a crisis of masculinity is not just the motivations for his unreliability, but also a whole further level of structure to the novel in which Stevens is aware of the way he is being received. I will argue here that Stevens' unreliability functions quite differently than how it is typically analysed, and that many reading experiences which are attributed to the structure of the implied author are explainable within narration. When Stevens is understood with this level of command, a somewhat different portrait of him and what he is saying about his crisis emerges. Through the alternative understanding of The Remains of the Day which follows I see new possibilities for the scope of both Stevens' consciousness and his crisis. Within this vision a clearer link is set up between these three novels in regard to the narrators' generation of their own private universe within a realist fiction. In doing so, a link is established between self-conscious narration, crisis of masculinity, and, as I shall explain, violations of realism.

\section{Stevens' Authorial Disposition}

Almost by definition, unreliability is a structure that enhances the synthetic dimensions of the narrative. It highlights the work of the implied author 'behind' the firstperson narrator and thus the artificial/constructed nature of the narration. However, if we see unreliable narration as being governed by crisis, it becomes something mimetic, something aimed at furthering the illusion of the narrator as appearing real. The cause of the narrator's distortions is a crisis existing within the storyworld psychology. Ishiguro therefore writes into the novel a storytelling device which draws attention to artificiality, while also almost preempting the reading of that artificiality and naturalising it within the storyworld. With this in 
mind, this section explores the way Stevens' narration, actions, and relationships reinforce this mimetic justification and make unreliability a humanising force.

Stevens is sometimes quite frank about what can be read as him overcompensating for feelings of anxiety in his role. These cases are most obvious in his digressions related to dignity. Stevens claims that “'dignity” has crucially to do with a butler's ability not to abandon the professional being he inhabits... the great butlers are great by virtue of their ability to inhabit their professional role" (43). In Lacan's terms, here Stevens articulates his split subjectivity, and the division between his inner experience and how he presents outwardly. It in fact suggests that Stevens is aware of the way he represses his personal and fragmented self. As Monika Gehlawat suggests, "the novel and Stevens must strive to express a self-contained and formally flawless existence" (491). The assumption of ironic distance, in which the structure of the work allows the reader to observe the repression of the experiencing self behind the narrator's back, is thrown into question by this display of awareness. Even if at this point in the novel he is not able to fully engage with what it has cost him, Stevens is, and has been prior to the reader's own knowledge, in the know about his repressive tendencies.

Much analysis of The Remains of the Day revolves around this question of how much Stevens knows of what he is revealing. ${ }^{22}$ Kathleen Wall analyses the essence of the narrative in the following way: "While Ishiguro has been quite careful about making Stevens's unreliability fairly obvious, he has also problematized the process of arriving at definitive versions [of events]" (30). How does this typical manner of analysing the novel and Stevens' awareness change when considered in terms of the crisis of masculinity? The significance of an experience common to all three novels is reasserted, in which the narrator seems far more in control than the typical first-person homodiegetic narrator. That is to say, he has control of the narrative order, of the novel's themes, even of how he is received as both character and narrator. The narrator is trying to accomplish something with his telling from the very beginning. This experience is tied to the understanding of the crisis as an all-consuming force, and it is precisely this that Wall strikes at with her comment on the difficulty of arriving at definitive versions of events. Our access to a reality outside of Stevens which we

\footnotetext{
${ }^{22}$ Cynthia F. Wong begins her chapter on "Disclosure and "Unconcealment" in the novel by asking, "Has Stevens mulled through these events long before and frequently enough so that what emerges now is not discovery so much as a private confession of those events?" (52). It is Adam Zachary Newton's claim that Stevens produces, "the appearance of a world which emerges from behind the one he discreetly and courteously escorts us through; we see that world, mostly unbeknownst to him, through a sort of discursive double exposure" (270). In both cases the focus there is an acknowledgement of how Stevens' level of self-knowledge fundamentally shifts the meaning of the narrative.
} 
might appeal to is very limited due to the extent to which he is in control. In this respect, the reading of crisis allows for many more elements of the narrative to be read as justified within the narrator's storyworld psychology. The pervasiveness of a crisis in the character narrator blurs the lines between mimetic, synthetic, and thematic explanations, foregrounding the fact that Stevens' narrating seems to be looking at, explaining, and responding to itself - and in doing so furthering the mimetic illusion.

Phelan notes how an overestimation of the mimetic dimensions of a text is "readers' default assumption," and that "experienced readers are of course very good at supplying mimetic justifications" (Living 25, 27). Stevens is believable and makes it enticing to form these assumptions because in him Ishiguro writes such a convincing reflection of a reasonable model of human fallibility. But the reading above is not simply an alternative proposed in order to preserve the mimetic impulse. This mimetic justification of narrative order and other elements can be read out of textual details, rather than readers' instinct. If the all-encompassing nature of Stevens' psychology is read as the result of a crisis which shapes both narrator and character functions, the extent to which Stevens is aware of what he is disclosing becomes less clear. This is exemplified in the dignity example quoted earlier, in which Stevens states in narration that he sees his role as being about stifling his emotional life. In the examples that follow I will argue that this case of awareness and others suggest that Stevens sees what he is exposing about himself through his placement of memories and knows what he has sacrificed. He is laying a trail for his audience, and is aware of their experience throughout his telling. Through this lens the means of exposing and correcting unreliability come from Stevens' psychology, fully located within the storyworld, instead of from the distance between what the narrator says and what the structure shaped by the author implies. Similarly, narrative order becomes explainable as a reflection of Stevens' train of thought, rather than as a way the implied author communicates through inconsistencies accentuated by the placement of scenes.

In Stevens' narration there becomes less and less which can truly be seen to violate mimesis. None of this is to naturalise the narrator himself, and it remains as Seymour Chatman observes, that a narrator of course "“come[s] by' his words because they are assigned to him" (Coming to Terms 85). Ishiguro does, however, establish within his novel a system which seems to explain itself through the attention it draws to its artificiality, but which, on another level, gives this very artificiality a justification within character psychology. It seems to be aware of itself as being written, but we come to understand why. 
In doing this Ishiguro deepens and complicates his themes: it is a narrative about the narratives we construct about our lives, after all.

How does this represent itself on the level of narration? As stated earlier, one way in which I identify Stevens' crisis as the structure responsible for what would otherwise be seen as synthetic and thematic elements of the narrative, is the way it displaces the ironic distance between action and commentary which typically characterises Stevens' unreliable narration. Take Stevens' account of Lord Darlington, one of his three central relationships in the novel. Darlington's is a useful case as it is informed by objective history, as well as, when it comes to the outcome of World War II, effectively universal norms against which to measure Stevens' version of events. Analysis of Stevens' reporting of Darlington typically views it as a case of widening the narrative distance between the norms of the reader and those of Stevens. For instance, Elke D'hoker writes that, after hearing Stevens' past and commentary on Darlington, and 'because of [the reader's] superior knowledge, a distance opens up between the narrator and the reader who is able to interpret many of Stevens' utterances in a different light" (153). Stevens as narrator in 1956, however, is of course as aware as anyone of the outcome of World War II and the truth about the Nazis. Even if Stevens maintains notions of class differences which violate modern norms, what is the "distance" between the reader and narrator here? Both know Darlington was wrong and even how his mistake casts a long shadow over Stevens' lifetime of service. The "different light" the reader grows to see Stevens' utterances in must be, then, in some way conscious, and something Stevens is aware he is producing. I would argue that, although some of Stevens' crisis is subconscious, in the case of disclosure about Darlington there is little significant synthetic operation of narrative distancing working behind the narrator's back. Just as the process of arriving at definitive versions of events is problematised despite unreliability being obvious, so is the distinction between what is read as Stevens' guilty subconscious tics and conscious intimations.

A distance does remain between the fictive narratee, who has heard of Darlington outside of Stevens' reporting, and the implied reader. Stevens' narratee exists largely as a receiver of his crisis, rather than conceived as an actual person. All his confessions and disavowals become more justified if there is a questioner, and I agree with Kathleen Wall's analysis that,

There is no physical presence in the novel to account for the 'you' he so frequently addresses... His address to this silent interlocutor is so frequently followed by some justification of his behaviour, that the pronoun 'you' automatically signals yet another moment of defensiveness, as if such a defence is necessitated by the (unarticulated) 
questions of the narratee that, in the absence of any physical presence, seem to voice Stevens's own unexpressed and perhaps even repressed certainties about his values and his career. (24)

If there is in fact no physical narratee, then it becomes clearer still that Stevens is subtly telling his audience about Darlington, with roughly full knowledge of how he is to be received, because he is challenged not by an "interlocutor," but by his crisis.

In any case, take the following example as one more distant from Darlington: when Stevens obediently sets about firing the Jewish staff of the manor. Although it is prompted by Darlington, this case is nevertheless Stevens examining his own disturbing actions. When Stevens is asked to fire the two Jewish staff members, he describes in narration how he was "not unperturbed at the prospect of telling Miss Kenton I was about to dismiss two of her maids" (147). And yet in Stevens' retelling of the scene he expresses no such perturbation, and in fact allows Miss Kenton to believe that he is undisturbed by Darlington's order. In this retrospective telling once again Stevens must be aware of the way he is complicit in antisemitism, and the way any contemporary audience will receive his narration. This is another case in which the reader is not learning about Stevens through a communication model which goes beyond his conscious participation, but rather can be read as him disclosing the origins of his crisis. His awareness extends not only to how his actions in the past violate contemporary norms, but also to how this is received. He is aware, in other words, of the parts of himself he is letting someone in on by sharing this. It can be read as a sort of appeal, where he stresses his complicity in the crimes of history in order to explain in the present just how bad his crisis truly is, and just how much he has thrown his energy into the wrong thing.

The episode of Stevens firing the Jewish maids is the closest reference in the book to the Holocaust. The great inhuman crime of the $20^{\text {th }}$ century, which Stevens never mentions and yet which looms over parts of his narration, is treated similarly to how Ono treats his wife's death in the previous novel. It is the very absence which speaks volumes-which points to the incomprehensibility of the catastrophic event. Thus, we understand through the course of the narrative that this is the event which has made the old way of doing things impossible for Stevens, and which has precipitated his old belief system crumbling.

The narrative order is such that the role these events play in Stevens' regret about the past is revealed slowly. However, running in close parallel to the unveiling of Ono's pre-war activities in An Artist of the Floating World, Stevens communicates deep shame around his association with his former employer. This communication is carried out in the style of 
unreliability typical of the novel, in which Stevens' commentary of events jars with their substance. This is most obvious in the two occasions when Stevens explains how he explicitly lies about his history of service with Darlington. In framing this memory, he insists: "there are many people these days who have a lot of foolish things to say about Lord Darlington, and it may be that you are under the impression that I am somehow embarrassed or ashamed of my association with his lordship, and it is this that lies behind such conduct. Then let me make it clear that nothing could be further from the truth" (132). In such commentary the reader understands the distance between what Stevens is saying as a narrator and what he has done as a character. But Stevens is also expressing an awareness of what the natural reading of his stories about Darlington mean. He has told his audience about how he as a character distanced himself from Darlington, and now he tries to suppress the natural inference from this. In doing so Stevens is acknowledging what he has been saying all along: he can deny that the obvious reading is the correct one, but he cannot deny that the impression that emerges from his narration points in one direction. He exposes himself, suggesting the explanation he offers for his lying, "though, of course, not entirely devoid of truth - was woefully inadequate" (132). So quickly does Stevens disclose this that he leaves the reader wondering to what extent it was he, rather than the implied author, who was responsible for displaying the distance between his narrating and character selves.

In this way, Stevens is presented as a very able storyteller in the tradition of Ono, navigating the differences between his experiencing and narrating selves. Through this section of the narrative, we see his weighing of different options culminate in a demonstration of his awareness of what makes a convincing narrative, what makes a convincing lie. We also see the way his alternatives work to convince others (Faraday), but not himself. For it is not others Stevens must satisfy, but really an internal pressure: his crisis. The fact that Stevens lies as a way of responding to his own crisis, rather than to outside attacks on Darlington as he alleges, is clearer still in his interaction with Faraday's friend Mrs Wakefield. When Mrs Wakefield asks about Stevens' association with Darlington she is doing so with no relation whatsoever to his politics. Her interest only corresponds in comparing Faraday's home to her own and questioning his claim that he has a "real old English butler" in Stevens (130). And yet still Stevens lies.

In the Mrs Wakefield incident we find a prime example of the way masculine crisis operates in all three novels. Crisis enforces a tunnel vision in which one can only see the world along its terms. Mrs. Wakefield's concern is only for whether an arch is truly $17^{\text {th }}$ Century, but Stevens feels the need to lie as he reads the full scope of his crisis into her 
question. The narrator's discourse in each novel is purposefully addressing crisis on some level; a discourse founded on crisis can only read things in terms of crisis. This can be seen as an extension of Ishiguro's concern with the way in which the real world and the imaginary world are always bleeding into one another. Stevens' narration is partly faithful to the real past, and partly faithful to his crisis and all its distortions. This rivalry between competing versions of the world is brought about through the reimagining of the traditional synthetic operations of unreliability, presenting these instead as a part of the mimetic illusion.

\section{Extending Stevens' Knowledge}

I set up this reading as going against the mainstream understanding of The Remains of the Day because so often readings interpret Stevens as in a situation of discovery through his narration, with the reader ahead of him. I see this situation as fundamentally changing the meaning of his narration. In this section I argue that through the preservation of the mimetic illusion and the corresponding awareness this understanding endows on Stevens, we see him becoming a storytelling force that masterfully builds towards a climactic meeting. With this in mind we get a clearer view of his crisis as the central drive behind the novel, and an explanation for the way themes arise again and again — not because the author is writing about an idea, but because the narrator cannot get it off his mind. Memories will often seem at first unrelated to the reader, but then return as important textural components of the story of his crisis. Observations and anecdotes seem at first tangential, before being revealed as significant parts of the puzzle of Stevens' crisis as he lays it out. This section discusses the way the technical point of the novel's mimetic dimension allows for new understandings about Stevens and his self-authorship.

The storytelling role of Stevens is traceable in the way he gradually exposes and leaks information to his audience. As has been explored, when Stevens recalls events such as Ribbentrop's visits to the house, or Darlington saying "Look at Germany and Italy, Stevens. See what strong leadership can do if it's allowed to act," and then declares that he is loyal to Darlington because "this employer embodies all that I find noble and admirable," the contradiction is not all going on 'behind the narrator's back' $(208,211)$. Stevens is not just aware of how wrong Darlington is, but is aware of what he is exposing to an audience. This is made most obvious in the string of final desperately defensive questions and excuses with which Stevens ends the penultimate chapter: 
How can one possibly be held to blame in any sense because, say, the passage of time has shown that Lord Darlington's efforts were misguided, even foolish?... It is hardly my fault if his lordship's life and work have turned out today to look, at best, a sad waste - and it is quite illogical that I should feel any regret or shame on my own account. (211)

The breadth of Stevens' awareness is again expressed when one of Lord Darlington's visiting friends, Mr Spencer, engages Stevens in a kind of humiliating question and answer through which to prove Stevens' political ignorance and the inability of any but a select few to run the country. Stevens at the time of the occurrence, and even as he narrates it, seems insistent that there was no humiliation in the questioning. But once again the narrative holds many signs that the weight of the event is communicated more deliberately, though not directly, by Stevens, rather than without his knowledge via implied author. One such sign that this sticks with Stevens more than he admits is that, when Darlington searches his memory, "What was it Mr Spencer said last night? He put it rather well" Stevens is immediately able to recall, "I believe, sir, he compared the present parliamentary system to a committee of the mothers' union attempting to organise a war campaign" (208). This is in complete contrast to his claim just prior that he had, "all but forgotten the episode by the following morning" (206). Stevens as narrator knows from his historical perspective that both Mr Spencer and Lord Darlington are completely wrong about democracy being "outmoded," but he also leaves a sign within character functions that he sees more than they do about the dignity every person is owed. Furthermore, understanding the narrative order as indicative of Stevens' train of thought reveals how he has connected this event to an encounter in his present-day journey. He pairs the humiliating memory with his meeting of Harry Smith, and a notion of dignity which conflicts with his own - and certainly with the way he is treated by Mr Spencer.

After his stay at a village and interaction with a politically minded local, Stevens claims the memory of Mr Spencer is prompted in order to demonstrate how wrong Harry Smith is in his alternative idea of dignity (as not "just something gentlemen have. Dignity's something every man and woman in this country can strive for and get” (195)). In fact, it relates to a different point Smith raises, but proves his claim precisely. This other point comes earlier in the evening, when the crowd discusses an aristocrat who used to live in the manor near their village, Mr Lindsay, and how he "May have had a lot of money, but he was never a gentleman" (193). Mr Lindsay "thought he was so much better than us, and he took us all for fools," and it is this same disdainful arrogance regarding class differences and their 
political application which Stevens remembers in Mr Spencer in the memory which follows (193).

Pursuing this logic, we engage with the placement of the scene as Stevens realising the potential for a new kind of dignity for himself. This scene once again displaces a part of the narrative which could be read as coming from the implied author, instead exploring the way the pervasiveness of crisis allows it to be explained by the narrator's psychology. In this way, what we have been reading as a synthetic function of the text in narrative order communicating unreliability can be explained with mimetic justifications. Stevens is therefore aware of the interplay between past and present in the movements of his selfreflection. Thus, explaining aspects which might appear thematic or synthetic as mimetic is not simply preserving the mimetic impulse one step further. It is central to the novel's exploration of storytelling's ability to assign significance in a life. In the scene in question, Stevens in fact sets up the memory in his transition from present to past as clearly having an explanatory power that he is quite aware of: "However, the unfortunate misunderstanding aside, there are perhaps one or two other aspects to this evening's events which warrant a few moments' thought - if only because otherwise they may come to niggle one throughout the coming days" (203). Lines such as this are vital, as they exemplify Stevens' overt practice and admission of what his commentary is constantly doing: commenting upon itself. Stevens showcases his authorial disposition here, playing his memories against one another in order to communicate his situation, his crisis, and how he has changed. The conclusion of such a reading is to move what is attributed to the implied author back a step. Even if Stevens' memories are used to access psychological information about him which he is unconscious of, the structuring of these flashbacks in relation to his present cannot be behind his back. This is demonstrable in the way we see Stevens throughout the narrative come to conclusions as a result of the placement of his history against his present self.

To return to the interactions with Harry Smith and Mr Spencer, Stevens narrates how the reoccurrence of this memory, and the events of the night before, have shaped his perception. The influence of this shameful memory is used to reveal the camaraderie Stevens feels among the people of the town. Most immediately, he suffered the same treatment as a "fool" by Mr Spencer as they did by Mr Lindsay. While meeting them he is in the disguise of a gentleman, but here the memory places his own experience as like their own. This is felt once again in his drive with Dr Carlisle the next day, and Stevens' judgement when Carlisle talks dismissively of Harry Smith's political involvement, "I was surprised by the tone of disgust that had entered the doctor's voice" (220). Stevens is actively responding to the 
arrangement of his memories in a way which suggests that he has more of a handle on what is being imparted via his memories than if we read this arrangement as a product of synthetic functions.

For Stevens, the overt meaning of his meeting with Harry Smith is the definition of dignity. This comes when Stevens is asked what it is that makes a gentleman, a true gentleman, not a Mr Lindsay or Spencer. Stevens' crisis of course immediately recognises a situation to project itself, and so he responds: "one would suspect that the quality being referred to might be most usefully termed 'dignity"' (195). In narration Stevens claims that he had no plans to bring up his favourite topic, "had the situation not suddenly demanded it of me" (195). The next day Dr Carlisle, upon learning that Smith was discussing dignity, asks, "Now that sounds rather philosophical for Harry Smith. How the devil did he get on to that?" (219). This new perspective from Carlisle reframes the scene so that, far from the natural answer which "seemed to cause much satisfaction," the raising of dignity seems unusual and forced (195). In answering Carlisle's question Stevens' answer reconstructs the picture with his crisis absent. Now Stevens is not the one who brought up dignity, but, "Mr Smith was stressing the importance of his campaigning work in the village" (219). Stevens the storyteller has written a motif into his work, but hides his responsibility for it on the level of character.

This is an example of the way Stevens' crisis operates as a theme-producing force. Thematic patterning becomes explainable through Stevens' storyworld psychology as well. This is another way in which Stevens seems to expose himself, and begs the question: does he really have a memory immediately accessible which aligns so perfectly with the arc he is currently on? Or are we in fact signalled that he is reading backwards - that he finds significant connections between the past and present because his crisis means he reads every situation the same way. Crisis is the drive towards theme in the narrative, and explains the pervasiveness of theme in a person's life while maintaining mimesis. Stevens' geographical journey therefore works as a template which allows him to project crisis onto real world events.

Along these lines, Chatman's definition of the implied author, though it is one which has undergone significant reworking and challenge, ${ }^{23}$ as "not the narrator, but rather the

\footnotetext{
${ }^{23}$ Shlomith Rimmon-Kenan argues Chatman's concept of the implied author is too connected to a communicative situation, in which it is an agent in an active relationship with the implied reader (91). RimmonKenan's own model in Narrative Fiction argues that the implied author "is best considered as a set of implicit norms rather than as a speaker or a voice (i.e. a subject)" (91). Here Rimmon-Kenan contributes to a wider debate around alternatives for the term or theory of the implied author, and leads into distinctions of less
} 
principle that invented the narrator, along with everything else in the narrative," can also work as a description of how Stevens' crisis works (Story and Discourse 148). The crisis does not of course "invent" him, but it does invent him as a narrator-in the sense that it drives him to tell, and is the ideology of his telling - and shapes the psychology implied in his narration. Similarly, masculine crisis is the filter through which everything in the narrative passes, and constantly problematises any definitive version of events. In Stevens we see the way the mind recreates itself in everything. In this way, some of what could be attributed to the author-image evoked by the work is attributable instead to Stevens' crisis which the text presents as a fictionalising force. It is fictionalising in the sense that the way crisis reproduces itself through the narrative in both narration and action continually forces a focus on memory, dignity, and lost time. It provides a storyworld explanation for the use of effects which draw attention to textuality, such as unreliability and overt thematising, but envelops all these operations within a mimetic psychology.

\section{Losing Realism to Crisis}

Often in the last pages of Ishiguro's novels the narrator's unreliability is more openly confronted, and the process of narrative is revealed as the narrator reaching a place where they can engage with their unreliability. The Remains of the Day and the conclusion to its "perfect unreliability," as Elke D'hoker has termed it, acts somewhat differently (152). With this idea of Stevens as behind his story to an unusual degree, the ending of his novel, often treated as a kind of realisation, takes on a different meaning. There is a realisation, as he reexamines, for instance, the memory in which he assumes Miss Kenton is crying in her office. However, I would argue that Stevens' ending is not the full moment of anagnorisis that it is sometimes read as.

As I have argued here, Stevens is not in the process of coming to new realisations about his life over the course of the narrative. Rather, his journey is a template onto which he projects the various anxieties over his past and his relationships which have been there at some level since Miss Kenton left Darlington Hall. Thus, he gives the audience all the tools they need to put much of his crisis and life together before the crucial Weymouth chapter.

importance to my argument about the text. My claim around the potential a crisis-based explanation has for extending mimetic justifications also works with a model of the implied author such as Rimmon-Kenan's. In such a case, the argument would be that the "implicit norms" structuring the implied author also take a step back if theme is seen as coming instead from Stevens' reimagining of everything in the language of crisis. 
The quote this thesis begins with, in which Ishiguro expresses what he was trying to capture in the final dramatic moment of A Pale View of Hills, is especially relevant here: "I intended with that scene for the reader finally to realise, with a sense of inevitability, 'of course, yes, she's finally said it.' Instead, it's a shock" (qtd. in Mason 338). The Weymouth meeting is precisely the author's attempt to address this in The Remains of the Day. Here there is no shock. There is that "inevitability" because Stevens has laid the way right up to this moment, has put all the proper memories in place and played them off against one another. The identification of Stevens' crisis of masculinity facilitates a new understanding of the process of narration. Rather than a progressing discovery, it becomes the articulation of a recognition which has existed prior to the events of the novel. This demonstrates Ishiguro's understanding of the storytelling process as fundamentally something much more shared between the speaker and the audience. It shows the importance of the elimination of distance between narrator and reader which I have spent this chapter exploring. This means something for Ishiguro's longer-term understanding of the unreliability as a humanising process, which the narrator is undergoing with their audience.

So, rather than the process of narration being a discovery of the disjuncture of history from his values, we come to understanding that this recognition is already there in Stevens. What Stevens expects the narratee to understand — what must be understood in order to make sense of the ending of the novel — can only be understood by granting Stevens an awareness of what he has been communicating. Stevens is aware he is in the role of telling, is aware of his audience and appeals to it multiple times. In one of the final instances of these appeals, he exclaims "for the likes of you and I, there is little choice other than to leave our fate, ultimately, in the hands of those great gentlemen at the hub of this world who employ our services" (257). In what way would such a claim, and his general feeling of a wasted life at the end of the novel, work coherently if Stevens simply expects to be taken at his word when he declares earlier, "it is quite illogical that I should feel any regret or shame on my own account" (211)? The implication seems to be that Stevens is ahead of these statements, knows what is being read into his life, and anticipates the conclusion. Although his journey involves an evolving thought process, it breaks the realist portrait Ishiguro has conjured in Stevens to suggest that he has suddenly arrived at a realisation at the journey's end, and has been oblivious to the obvious meaning of his storytelling. ${ }^{24}$ All the signs and memories have led up

\footnotetext{
${ }^{24}$ As Meghan Hammond argues: to read Stevens as naïve "robs him of what little agency he has, while absolving him from responsibility for his past in the infamous history of Darlington Hall" (96). In contrast to Phelan's view of Stevens, Hammond attributes to Stevens a self-awareness, as I do, and finds that Stevens'
} 
to this point too cleanly for this to be something fully new. It is true that he sees now what his story as a story signifies - that it occurs to him the actual meaning of what he has been saying - but the road to this has been laid from so early on that a consciousness of where he would arrive must be given to Stevens.

Thus, what these crises ultimately appeal to is the storytelling impulse. They provide the delimitations which turn a life into a narrative. Psychological preoccupations replace theme, or at least force it back far enough that the theme becomes the act of storytelling itself. At the end of the novel Stevens does not come upon his realisation through his actual life, but rather by what the telling of his life implies. In the final scene of the novel, at the moment of realisation and despondency on the pier, he is fully Lacan's image self, where he does not engage with his life as an actual participant, only as an observer, imagining what someone else might be seeing.

A key element of crises of masculinity and of this role of storyteller which is shared between An Artist of the Floating World and The Remains of the Day, and reaches its height in The Unconsoled, is a mistaken sense of priorities. He has valued art or work above emotions or relationships and now it is too late. Recall the line spoken by Setsuko to her father at the end of An Artist: "Forgive me, but it is perhaps important to see things in a proper perspective... Father was simply a painter" (193). Ono leaves it unanswered to what extent his over-prioritising art has made him feel more responsible than is rational, but with Stevens his narrative is directly engaged with the realisation that his own over-prioritisation of his career has taken an irreparable toll on other aspects of his life. Stevens' persistently repressed desire for "human warmth" has been rebuffed his whole life by a masculine mythology justifying his constraints by exaggerating the importance of the role of butler (245). Thus, Stevens finds some aspect of the role of butler in everything, and even on that sad pier at the end of the book, he just so happens to be approached by a passing butler. Once again, his crisis consumes his vision to such an extent that it betrays itself. In his representation of a world where a butler's values are as central as he believes, Stevens discloses the way he has overvalued his role as butler.

This sudden appearance of an unnamed character has perplexed studies of the novel. Phelan asks, "by what rule of literary probability can Ishiguro justify having Stevens meet a

"unnecessary or spurious" explanations "reveal continuously and subtly [his] desire to control his autobiography" (96). 
retired butler who just turns out to give him wise and consoling advice?" (Living 63). ${ }^{25}$ Once again the reader is faced with an improbability too fanciful to square with this form of realist fiction. Beyond the occurrence itself, Ishiguro has Stevens intimate in several other ways that something odd is taking place. It occurs to Stevens, "In fact, I do not think I registered his presence at all until he declared out loud, 'Sea air does you a lot of good"' (253). The man just appears. And then a page later Stevens is confessing the tragedy of his wasted life, while "the man [says] nothing" (255). Far from observing his code of never "removing one's clothes in public," in his confession he suddenly and uncharacteristically bares his whole soul before this stranger.

Having placed this novel between An Artist of the Floating World and its traumabased synchronicities, and The Unconsoled in which there are no limits to what can plausibly be seen as illusion, I read this "curious companion" as being a product of Stevens' imagination (256). Faced with the deeply painful fact of Mrs. Benn's rejection of him and the realisation that he has come to his newfound knowledge too late, Stevens reaches the depths of his crisis. Devoting his life to being a butler and the ideology paired with that has cost him everything. And central to this mistake was a calculation which put the influence of butlers, and a distorted view of dignity, at the centre of the world. In this state of desperate masculine crisis, he simply denies the possibility that what has made him a man has also cost him his chance at a genuinely fulfilling life. With the possibility of Mrs. Benn returning to his life eliminated, Stevens realises he is past the point of no return. The illusion of another butler is constructed to cope with this fact in two ways. Firstly, his presence cements in Stevens' mind the place of his profession in the world as something visible, acknowledged, and sympathised with. There are butlers everywhere. Secondly, the illusion tells Stevens all the right, consoling things which ensure the insulation of Stevens' crisis: "Don't keep looking back all the time, you're bound to get depressed" (256). Instead, he becomes oriented back towards the big house and towards service. Stevens in this way falls into the pattern now emerging for Ishiguro's narrators, of distorting the world as a way to cope with it.

I do not wish to contend that Ishiguro has obviously made this an illusion summoned by Stevens - that this is the inevitable reading. On the contrary, it is precisely in the doubt over any definitive interpretation that Stevens' crisis of masculinity reasserts itself. As the

\footnotetext{
25 The answer for Phelan is that the unlikely figure is used to "call attention to our experience as readers of this narrative and to readerly desires that have not yet been fulfilled" (Living 63). Phelan argues the retired butler is the narratee themself, as well as a stand-in for the flesh-and-blood reader, simulating the advice the reader would like to impart to Stevens after his painful meeting with Mrs. Benn.
} 
complications of Stevens' unreliability seem to be tying up at the end of the narrative, suddenly we have this violation which seems to 'break the rules' in a similar way to the reoccurring symbols in Ono's most climactic memories. What has been read as "perfectly unreliability" and is always spoken of as Ishiguro's central realist work, ends with a rush into distortion (D'hoker 152). I would furthermore argue that the fact that we are able to accept even the possibility that Stevens is imagining the conversation here is testament to the fact that Ishiguro has built distortion into the novel as a whole.

And so, Stevens' final affirmation that "in bantering lies the key to human warmth" feels like progress of a kind, but really represents a doubling down on all his previous mistakes only in a different key (258). In fact, the concluding sentences of the novel are devoted to someone else. Stevens resolves to practice ever the art of bantering harder than ever, and his final hope is "that by the time of my employer's return, I shall be in a position to pleasantly surprise him" (258). Farraday as an employer might be more generous than Darlington, but this is not Stevens showing signs of beginning a new life on his own terms. With the reading of Stevens as a self-conscious narrator with an authorial disposition, this final attempt at buoying himself can even be read as a retreat back into the comic tone from the beginning of the novel, with Farraday poking fun at the deadpan Stevens. This does not work anymore as Stevens can no longer be read as the truly impassive model butler. The ending of the novel is a return to his deep investment in his identity as butler. In the rivalry between the image in the mirror and the self of felt experience, the image triumphs. His work is what makes him a man, and his final commitment is to improve at it on his employer's terms. In returning to the attempt at deadpan humour from the beginning of the novel via the motif of banter, Stevens is engaging with himself as the image of the stony-faced butler, not as the human who we have read experience heartbreak and self-realisations. In this sense, the uplifting note Stevens attempts to strike through the conclusion is used "in order to signify something quite other than what it says:" the return to crisis (Lacan 744).

Thus, the ending imposes Stevens' exclusive "language" in Bakhtin's sense, in which the world is organised fully along the lines of what matters to him, even to the exclusion of reality. Adriana Neagu, in her Bakhtinian reading of The Remains of the Day, draws on Bakhtin's theory that the ontological status of the novel includes a plurality of voices to argue that, "Ishiguro writes poems in prose... The poematic symphonism of Ishiguro's prose is too unitary to be novelistic" (270). I would argue that the unitary nature Neagu identifies comes not from something essential to Ishiguro's prose, but rather his narrators' attempts to become not only the "voice of reason," but also the very source of reason and logic within their 
universes. It represents their attempt at masculine domination over their narrative as the ultimate display of masculine crisis. The novel ends in this display, Stevens conjuring a whole new person out of the substance of his crisis. This domination over reality will be demonstrated most forcefully of all in Ishiguro's surreal masterwork of crisis of masculinity, The Unconsoled.

It is with crisis as with the novel generally, that it both frustrates and facilitates the discovery of truth. And the most central case of this is the simple impossibility of these worlds being as focussed on their respective fields as their narrators try to convince us they are. Setsuko's point quoted earlier strikes so powerfully as the reader has become wrapped up in Ono's conception of the world with art at the centre. The realisation rushes home that the reader has come to share Ono's preoccupation, accepting how responsible he as an artist is for the causes of war. Similarly, in this novel Stevens' insistence on the significance of the role of butler, on the subtle importance silverware plays in state affairs, betrays his anxiety over the actual meaninglessness of his part. Stevens refers to a world of famous butlers, appealing to the narratee, "You will not dispute, I presume, that Mr Marshall of Charleville House and Mr Lane of Bridewood have been the two great butlers of recent times" (34). The misplaced priority bleeds out from the narrator into the focus of the world to such an extent that butlers simply appear before him.

Moving on to The Unconsoled and the culmination of Ishiguro's series on the crisis of masculinity, a whole world is conceived of oriented towards its narrator's misplaced value in music. Each of these men is driven to storytelling because they see the ways in which they have misjudged what matters, have thrown their lot in with one version of being a man which has now failed them. Stevens is clearest of all three in his expression of understanding this failure, and in the depression it causes in him. But the narrative still presents the mistaken priority as at the heart of the world. In this way the reader feels the narrator as behind the text, because Stevens' priorities are woven into the fabric of the text even as they are exposed. The Unconsoled is Ishiguro's follow-through in the sense of untethering this storytelling impulse from realist touchstones, with full authority granted to the expression of masculine crisis on its own terms. The Remains of the Day is the version of storyteller in 
crisis with realism more fully present, before it is suddenly violated in the escalation to the final addition to Ishiguro's novels of masculine crisis.

As Chatman writes, “A narrative text (like any text) contains within itself, explicitly or implicitly, information about how to read it" (Coming to Terms 83). For The Remains of the Day this implicit guide is to be found in Stevens' anxieties and how he subtly expresses them in the space between his narrating and character self. And yet still Stevens as a storyteller is aware of this gap, aware of the way one element of his story calls another into question. In fact, it can be understood that he is not only aware of the assertion of his crisis that this unreliability constitutes, but that it is in some way deliberate. The crisis of masculinity demands that it be expressed, and Stevens' discourse through The Remains of the Day is this expression. The novel becomes to a great extent self-sufficient in providing its own meaning, and demanding it be read on its own terms, as theme and coherence, structure and character all come from within the mind of the narrator and unlikely storyteller, Stevens. 


\section{"Crushed Cadences": The Unconsoled and Controlling the Narrative}

For a man who no longer has a homeland, writing becomes a place to live.

-Theodor Adorno, Minima Moralia

Ellie Ragland-Sullivan points out the essential 'catch' of masculine crisis (and unreliable narration): that "paradoxically [Man's very] effort at mastery shows a lack-a lie as the basis of symbolic" (75-6). There is a deep vulnerability exposed precisely in the defensive attempt to control the narrative or control a narrative. Ragland-Sullivan's expression is pertinent not only to the way unreliable narration draws attention to crisis in its attempt to conceal it, but also shows how masculine crisis is ultimately about power. This "effort at mastery" is the motivation behind the "self-authoring" each of these narrators has been engaged in. With the final addition to Ishiguro's crisis trilogy, power is put front and centre to an even further extent. The previous chapters have looked at masculine crises' drive for control, particularly on the level of narrative structure. Ono lays out an intricate series of episodes in order to communicate the true weight of different events. Stevens navigates a constant awareness of how he and his past are being received in order to communicate more than he says. Yet, at least on the level of character, perhaps the clearest fact of The Unconsoled is that Ryder has no control over events, or even over his schedule. ${ }^{26}$ Despite this appearance, in this chapter I will argue that Ryder exhibits a kind of domination and desire for control over his narrative world to an even further extent than earlier narrators. Although Ryder the character might seem swamped with responsibility to the point that he cannot operate at all, this universe represents his individual worldview come to life. The world of The Unconsoled constitutes almost a private language through which Ryder can express his crisis of masculinity, and which the logic of his traumatised psychology governs.

\footnotetext{
${ }^{26}$ Katherine Stanton illustrates this powerlessness in her commentary on the novel by drawing attention to how "'Finds himself" is the verb construction The Unconsoled uses with regularity to describe Ryder" (9). For Stanton this suggests the extent to which events are out of Ryder's hands, as well as the narrator's "belated selfrecognition" (9).
} 
What distinguishes The Unconsoled from Ishiguro's previous novels is of course the disorienting nature of the storyworld and the confusion surrounding its material laws. This is typically explained as being part of a dream world and following a dream logic. Stanton explains how in The Unconsoled, "The dreamwork renders manifest, in distorted form, the latent or unconscious dream-thoughts" (16). In Frederick Holmes' reading, "space and time for Ryder and the numerous characters whom he encounters have an unpredictable elasticity just as they do in dream. And those other characters are related to Ryder just as the figures in our dreams might well be related to us" (12-13). Pierre François has termed this narrative mode "oneiric realism" (79). My own analysis does not necessarily contradict this reading, but provides a different focus. In my reading of this novel as part of a crisis trilogy, there is a Ryder who exists in a world like ours, who we construct an outline of based on the information we receive about his crisis. ${ }^{27}$ The reader is able to glimpse someone who has suffered traumatic emotional damage as a child, who has sacrificed whatever personal happiness he might have enjoyed in order to satisfy the exacting demands of his professional life, who fears losing his family — or already has. As Gary Adelman explains: "The plot, or movement from encounter to encounter, is a seismographic record of Ryder's psyche. On the surface its line appears haphazard, yet in the implied why of the sequence, he is intimately disclosed" (168). ${ }^{28}$ This character narrator represents a figure like Ono or Stevens who has gone one step further into crisis. In the chain from crisis of masculinity, to self-conscious narration, and finally into violations of realism, The Unconsoled begins already solidly in the last stage.

In the prior novels, the reader comes to understand memory as a form of indirect communication about the character narrator's emotional state. I argue in this chapter that moments of surrealism in The Unconsoled act as a similar kind of indirect communication of masculine crisis. For example, take the pattern of dysfunctional families through the novel: Gustav and Sophie, Mr. Hoffman and Stephan, Ryder's parents and Ryder, Ryder and Boris.

\footnotetext{
${ }^{27}$ A. Harris Fairbanks's reading is not dissimilar. As she suggests, "the events are not those of a proper dream [but] they belong to a world in which events and the main character's psychological reactions operate as they do in a dream" (604).

${ }^{28}$ I draw on Adelman's study of the novel several times in this chapter, finding his stitching together of the myriad images of abandonment to be effective in getting a clearer account of Ryder's trauma. His analysis is weakened, however, by the peculiar reading with which it ends. Adelman claims, "there is still that something else that [Ryder] as a human being knows about himself that eludes external definition, but that can be felt about him. I sense that Ryder is a potential paedophile... Paedophilia seems to fit Ryder's personal history and his inability to form close emotional ties" (178). The surrealism of the novel removes the possibility of a definite conclusion, but I see Adelman's theory as fundamentally contradicting the understanding of the novel's distortions as confessional, subconscious divulsions.
} 
Meaningful communication breaks down in every one of these relationships. The recurrence of this dynamic again and again is strongly reminiscent both of Ono's visions of burning and his blurring of relationships over the course of his life in An Artist of the Floating World. This reminiscence is demonstrative of a central relationship between The Unconsoled and the earlier works: the "dream-like" distortions of this world act as a counterpart to, and in fact the developed version of, the function of memory in the prior novels. Therefore, it is my claim that the difficulties and unorthodoxies of this novel result from a heightening of the same principles which formed the distortions in the first two parts of this trilogy. The dreamlike world of The Unconsoled emerges from its narrator's crisis of masculinity, just as distortions in the form of unreliability in the earlier works do.

Ryder's crisis of masculinity results from an inability to properly assign importance in his life. His crisis is one of responsibility to others because his absolutist performance of a role which establishes him as a man has made it impossible to distinguish which of his bonds are truly meaningful. Thus, his crisis reconstructs the communal, political situation of a city so that his piano performance has real heroic potential. He sums up his perverse reading of the world, his failure to recognise what is truly important, in an argument with Sophie where she urges him to give up touring: "You don't know what you're saying! Some of these places I visit, the people don't know a thing. They don't understand the first thing about modern music and if you leave them to themselves, it's obvious, they'll just get deeper and deeper into trouble. I'm needed, why can't you see that? I'm needed here!" (37). His sense of masculinity relies upon his artistic achievements; thus, he focuses on that to the detriment of his family life. As we learn through Ryder's storyworld distortions, this confused sense of priorities is itself a result of his inability to win parental affection as a child. He is called to be a father and husband, but finds this impossible to balance with his role as an artist and man. $\mathrm{He}$ is overwhelmed by responsibility, which he represents in the strange world of the novel through the countless minor tasks he must devote himself to and which suddenly take up absurdly momentous levels of importance.

Through this, The Unconsoled reaffirms the extent to which crises of masculinity generally, and Ryder's in particular, are about identity. Ryder, as a result of his failure to distinguish what really matters, has lost a sense of himself. He spends his life on musical tour, in "hotel room after hotel room," and can no longer recognise his own home or family (38). His formerly unitary self comes to pieces, with memories dispersed among other characters. This chapter will look at the three techniques which Ishiguro uses to illustrate 
Ryder's crisis of masculinity and drive to power over his narrative: appropriation, history, and language. Ryder's use of each of these is established in the earlier novels.

The first way in which Ryder's crisis of responsibility and identity is demonstrated is appropriation - a technique already explored, particularly in An Artist of the Floating World. This chapter will analyse the acceleration of this technique in Ishiguro's finale to the trilogy as it becomes a central means of communicating crisis. History and language, meanwhile, are both connected to masculine crisis operating as a "relativising" power. A shared experience of the world is broken by the crisis of masculinity. In The Unconsoled there can be found a personal history, a personal language, a whole storytelling world reconfigured in keeping with the struggle to assert individuation. I will argue that it is no coincidence that here, at the height of crisis, history drops out of the narrative, whereas it was such a fundamental feature in the prior novels. History, and the way it provides an outside context beyond the individual — its putting things into perspective and proportion — clashes with a crisis of masculinity. And so, with Ryder fully in control of this universe, there is no true past. I draw most heavily on Bakhtin in this chapter to make a similar point about the communal force behind language. The way Ryder's subconscious tries to reimagine language itself as something individual is testament to how The Unconsoled presents an attempt to reinvent a universe along the lines of the all-encompassing crisis of masculinity. Drawing on the representation of these three techniques in prior novels and how they come to life in this intense final iteration, this chapter analyses a novel in which the crisis of masculinity has fully prevailed.

\section{The Alter Egos of Ryder}

Social theorist Zygmunt Bauman describes the nomad in the modern world as one who "wanders between unconnected places as they move through identities" (66-7). Recall the difficulty Ono has in placing himself after the death of his family - the way he confuses his own actions and words with those of others. For Bauman here, and for Ishiguro, the aftermath of tragedy has a profound effect on identity. Ishiguro expresses this through the technique of "appropriation": an almost literal way of moving "through identities." Ishiguro himself explains how "We tend to appropriate other people - more than we perhaps care to admit. We perhaps don't see them for what they are; they become useful tools" (qtd in Holmes 18). The treatment of other characters by the narrators reaches its peak in The Unconsoled, where any sense of other characters being truly separate from Ryder becomes 
dubious. Peter Mathews describes how, "Ishiguro strategically places mirrors inside the narrative dreamscape to connote these moments of doubling" (78) ${ }^{29}$ In what follows, I want to show how appropriation in The Unconsoled is used to orient an entire world toward Ryder's trauma, to the exclusion of any other consciousness.

An early example of appropriation which establishes the technique in the narrative, as well as the surreal tone of the novel more generally, takes place while the hotel manager's son, Stephan Hoffman, drives Ryder and Boris around the city. As Ryder observes Stephan a change transpires, and a "realisation" occurs to him: "The young man remained silent for a long time and I wondered if he had become angry with me. But then I caught sight of his profile in the changing light and realised he was turning over in his mind a particular incident from several years ago" (65). These sentences of transition spell out the subjugation of someone who moments ago had had his own internal territory. Now this separate person is collapsed into a way of communicating the crisis of masculinity. New rules are laid out within the storyworld: no consciousness is now beyond Ryder's access or control. Consequently, the memory Ryder watches through Stephan is one perhaps very close to the root of his crisis of responsibility and failure of proportion. He sees "Stephan" (himself) as playing some part in destroying his mother and father's relationship by disappointing them in a piano performance of the past. Ryder explains how,

Stephan had turned over every aspect of that evening's events - just as he was to do again and again over the following years. The anguish he felt each time he recalled that occasion had gradually diminished with time, but now the steady approach of Thursday night had brought back many of the old terrors, causing him yet again, as we drove on through the rainy night, to be transported back to that painful evening of several years ago. (71)

There is something about this painful memory which makes Ryder unable to say it in his own voice - unable to attribute it to himself — although it is clearly his. In line with the model replicated in the first two novels of this trilogy, I argue that it is precisely the importance this memory has to Ryder, the way it has shaped him and informed his present-day crisis, which makes him unable to claim it as his own (while in other ways exposing it as his). After Stevens' father dies in The Remains of the Day, it is only through the dialogue of other

\footnotetext{
${ }^{29}$ Rather than reading the appropriation of the novel as an absolute privileging of Ryder's experience, Mathews argues that "Ishiguro repeatedly subverts the centrality of Ryder's subjectivity by allowing his position as narrator to overflow its boundaries" (80). Mike Petry similarly sees The Unconsoled as "a patchwork, an orchestration, of many different narrative voices" (148).
} 
characters that we find out that Stevens has been crying, without any direct acknowledgement from him as narrator. ${ }^{30}$ Ryder's appropriation here acts similarly: he leaves the dirty, awkward work of describing traumatic emotional history in the hands of others. The contradictory demands to both tell the story of crisis but also to repress emotional expressions warp reality to communicate indirectly.

The novel's conflict between the voice of narrator and character becomes more expressly manifest here. Stephan, emerging from a community of dialogue and with an expansive, connected life beyond Ryder, has his personal expression collapsed into a projected memory of the narrator's singular voice. In Bakhtinian terms, Ryder reduces the level of heteroglossia of the novel through crisis, as he transforms the language of others into a means of communicating his personal crisis. We begin to see how Ryder's crisis requires its own language, separated from dialogue. Ryder provides this by practically eliminating the existence of others. All other voices are speaking indirectly about what Ryder's parents did to him, and what he has done to himself. Other people are simply another indirect line of communication used to express the crisis of masculinity. A whole life and personal history is represented in this way, as Adelman explains:

Ryder plays his own father, re-creating his family of origin in his relationship to his wife Sophie and his nine-year-old son... The relationship of Stephan Hoffman to his parents re-enacts Ryder's life until his mid-twenties, when his career takes off. Subordinate characters to whom other memories are attached flesh out Ryder's psychobiography. Brodsky the ex-orchestra conductor... represents Ryder's futurethe future ordained for him by his father-whereas a rehabilitated Brodsky courting Miss Collins... enacts Ryder's fantasy of changing the future. (167) Stephan's case quoted above is representative: through Ryder's surrealist storytelling there becomes no distance between the history of others and Ryder's own past. The suggestion is that in any sign of an unconsoled life Ryder sees himself. There is a boundless expansion of himself through other personalities and histories. This fantastical version of alternative communication becomes clear in the context of An Artist of the Floating World and The Remains of the Day. The echoes of the technique can be found in the earlier novels: clearly in how Ono sees grief and guilt all around him, but also in how Stevens finds challenges to his way of life when none have been posed - except from within. tragedy and shame haunt and

\footnotetext{
${ }^{30}$ Kathleen Wall makes the point that, "Ishiguro leaves us uneasily wondering how responsible Stevens is for communicating his grief to us by reporting that others have observed his feelings" (28).
} 
possesses all three men in the form of their crises to the extent that they can barely read emotions outside of that mode. This inner anxiety is projected outward onto others. Although all these cases leave the narrators more exposed, I would argue that each of them also represents their crises' "effort at mastery." This style of projection, appropriation, suppresses the true sense of an outside world and leaves only itself represented. With Ryder's masculine crisis reaching the level that it has, a question is left of whether any other character even authentically exists in his private universe, or whether all are simply iterations of himself and his past.

This example with Stephan occurs early in the novel, and its placement leaves the door open in all future interactions to the possibility that Ryder is once again engaged in some level of appropriation. For example, the attempts by the retired composer Brodsky and Miss Collins to mend their relationship become a clear approximation, or imagining, or fear, of Ryder and Sophie's own future. Despite the apparent disorder of the narrative, the recurrence via appropriation of the same images and relationships in different characters displays the pervasiveness of Ryder's crisis. The whole novel's apparent engagement with a narrative present, Ryder's visit to this city is in fact a substitute used to represent the pattern of his past and future, which is simultaneously represented as his present through Boris, Gustav, Christoff, Hoffman, Brodsky, Stephan, and others (just as Stevens' journey is used as a template through which to reassess his memories). This is the pattern of Ryder's life, and so when it is revealed he is going from this performance immediately on to another in Helsinki at the end of the novel, the implication is that this crisis is set to repeat with the same appropriations taking place with new "hosts." In this respect appropriation is once again a central display of mastery driven by the crisis of masculinity-nothing matters except what matters to Ryder. All other concerns fall away but Ryder's need to achieve manhood through approval from his parents.

Thus, the interior life of Ryder becomes externalised through appropriation. In the earlier novels this was communicated through narration, but here it is seen as physically real (as it was at the end of The Remains of the Day). Ono's patterning of his life acts as an alternate means of communicating his loss - a gesture towards a tragedy withheld from direct narration. Ryder, or Ryder's subconscious, inherits this need to tell the story of crisis via indirection. The continuous gesture for Ryder is toward a jumble of events of a similar note, evocative of one another. Ryder's overwhelmed, traumatised memory is teeming with tales of silent, withholding parents and bereaved children, which he projects everywhere through 
appropriation. The establishment of themes within the mimetic illusion is the analogue to this in The Remains of the Day. Stevens ties everything back to dignity in the same way Ryder's every interaction is drawn towards abandonment, alienation, or music. Only Stevens makes the mistake of inflating the importance of silverware, but in this world controlled by Ryder everyone buys in to the importance of his recital. This is what is meant by "heightening": now that the pretence of a realist universe has given way, the internal distortions of Ono and Stevens have become expressed through Ryder's reality.

\section{Crisis with no Past}

Appropriation demonstrates how the use of surreal elements in The Unconsoled correlates to the use of memory in the earlier novels. They are used in similar ways to give background to the narrators' present state of masculine crisis. However, one fundamental absence in The Unconsoled makes the inclusion of memory impossible. This is the absence of history. ${ }^{31}$ Appropriation and other techniques which evoke the surreal texture to the novel become surreal, I will argue, because they are memory within a world with no history.

In the previous novels, history is built into the structure of each to demonstrate its potential for resolving crises. Readings of each of the earlier novels by Cynthia Wong and James Phelan demonstrate this. First, Wong and Ishiguro on An Artist:

According to the author, an advantage of using a 'diary narrative is that each entry can be written from a different emotional position. What [Ono] writes in October 1948 is actually written out of a different set of assumptions than the pieces that are written later on... so we can actually watch his progress, and so that the language itself changes slightly.' The shifts between entries are subtle and they suggest Ono's modification of his stories as he moves forward. (Wong 38)

Clearly stated dates begin sections of Ono's story, marking the progress of Japan being rebuilt, his daughter's wedding arrangements, and his own coming to terms with the past. Ono is constantly engaging with how the world is becoming a different place, and his corresponding change is accentuated through the structure of his novel. Phelan makes a similar point about the structure of The Remains of the Day:

\footnotetext{
31 "Memories" do rarely occur to Ryder towards the end of the narrative, but they are not a primary means of communicating his crisis. Memory is not the basis of narrative structure.
} 
Each act of narration, except "The Prologue" and "Weymouth," also leads Stevens into memories of his more distant past. This arrangement means that Stevens narrates each instalment from a different place, both literally and emotionally, because in those memories Stevens almost unwittingly conducts an examination of his life. More specifically, the act of narrating leads Stevens to reflect on key moments in his life. (Living 32)

Once again in Stevens' narration there is an orderliness which spells out a connection between time and resolution of crisis. Crucial to both these acts of narration is an emotional shift that occurs through history moving forward. This is impossible in The Unconsoled. Ryder finds himself at a dead end within his crisis. He is stuck in a moment in history-or many moments - but all play out as though happening to him now, and all feel imminent and immediate to Ryder. He has not moved on from his parents' failed marriage or from the need to seek their approval, so all these events reoccur in the present. This imminence of the past occurs, though in a more minor degree, for both Ono and Stevens as well. The reader experiences them dwelling on the same events to the extent that they do not truly experience the present. We can see that Ono has no real life anymore without his wife, and Stevens at the end of the novel dismisses the real progress he has made to return to Darlington Hall. But Ryder's comprehension of the world is so compromised by his masculine crisis that he cannot even distinguish between the painful events of the past and the living present. His whole life revolves around the fantasy of a mythic performance which will win him approval, and in doing so assert his authority and masculinity.

Using Bakhtin's framework, history is a process of dialogisation, a kind of growing social conversation full of references to draw on, that signify the spirit of community. Dialogised heteroglossia consists in the evolution resulting from members of a community hearing one another. Therefore, the resolution of masculine crises through an acceptance of history and time's movement necessitates an acceptance of other voices into the narrator's worldview. For dialogue to be possible there must be a plurality of positions. This is an avenue unavailable to Ryder in his ahistorical, atemporal world, and it is in fact precisely because his crisis is irresolvable that his world becomes ahistorical. Therefore, it is Ryder's very effort to assert mastery, to subdue competing voices and versions of events, which traps him, and which draws attention to his powerlessness to escape his trauma.

Ono and Stevens have a dramatic historical background through which to ground their experience, World War II. Ryder has nothing except his traumatised childhood. The same process which made everyone implicated in the historical events of the prior novels makes 
him isolated. The cause of his crisis seems to be purely personal tragedy, mistreatment by his parents which he recreates in his relationship with his son and wife. He dimly recalls his childhood friend saying, "When you get married, it needn't be like it is with your mum and dad. It won't be like that at all" (172). But the emotional damage done to Ryder has wounded him in such a way that he cannot move on. Worse still, masculine crisis means that, in a way, he does not want to move on. The universe he has created through his subconscious gives him a perverse kind of control in which his voice is privileged, and everything is designed based on what matters to him. Masculinity, like the need for his parents' approval, might be hateful to him, but he still needs it to maintain this whole illusion.

Earlier chapters have discussed the way in which Ono and Stevens lack a perspective to see beyond their own environment or to stand outside the values of their time-facts both they and the reader become aware of as they construct their self-portraiture through history. Ono finds the weight of responsibility from history so inescapable that he cannot live in the present, or experiences the present only as reminders of tragedy. Stevens is crushed by anxiety following the realisation that time has kept going and he is excluded from it; that Miss Kenton can experience love, but he cannot. These narrators are really no longer a part of the present world in which they find themselves. And now their experience has become reality in Ryder. In the internal world of the novel, Ryder makes himself too essential both on the level of character (he must speak at a stranger's funeral, he must defend the dignity of the city's porters) and in his role as narrator for a history to move on without him. Even the history which pre-dates Ryder in the city is clearly constructed for him to respond to: he is the perfect man for the job, and the city has pinned all its hopes on him. The vague crisis the city is going through must be resolved through music, and so Ryder's masculine ego is fuelled by assigning his actions some heroic potential—just as Ono's and Stevens' are charged through the overemphasis on the roles of painter and butler. But the centrality of the looming performance is a non-historical event. It is simply a fixture in Ryder's subconscious, representing the constant need to prove himself. Thus, there is no moving on, the only movement is through to the next city, already presented as a replay of the crisis.

\section{Monoglossia as Self-Authorship}

For both of these phenomena - the appropriation of other characters and the elimination of history - there is a direct connection to self-authorship. When Ishiguro's narrators tell the story of something else, they are constantly also talking about themselves. 
Character narrators are, like flesh-and-blood readers, always perceiving the world as the interpenetration of real and imaginary forces. Through the broad consensus around reality, we develop a worldview or language, a collaborative process. This understanding is violated when Ono explains how he experiences his memories blurring into one another, or when Stevens pours his heart out to an imaginary sympathetic figure. Their descension from the collaborative process and attempt to mark out a language or experience as unitary and total is an attempt at Bakhtin's concept of monoglossia. The word is not something shared, language is not about intelligibility-everything is about the crisis, and therefore about power. As Bakhtin reveals, “only error individualises" (Problems 81 ). The crisis of masculinity makes these narrators pursue a kind of power which ends with conceptualising the world in words and ways which only they have control over. Thus, we experience Ono's universe for moments, and begin to descend into Stevens' universe at the end of his narrative, but, in its individuation through surrealism, we truly come to live in Ryder's universe of crisis. ${ }^{32}$

This drive toward monoglossia is most apparent in the discussions of music in The Unconsoled. Many or all of Ryder's projections and distortions of the narrative can be read as explications of where his unfulfillable sense of responsibility comes from. He has proven unable to live up to his duties to his wife and son, so he justifies this by inflating the importance of his duties in the realm where he is most capable, music. He therefore presents a world in which contemporary music has lost its ability to move and excite its audience. The whole cultural life and international relevance of a city hangs in the balance. As we learn from the appropriation of Stephan, Ryder has convinced himself that it is music, and his musical failures, which ruined his parents' relationship. Other relationships in the novel too, most centrally that of Brodsky and Miss Collins, will live or die by the success of "Thursday night." The implication is that the anonymous characters, the entire population of the city in fact, join in the anxiety and debate over Ryder and Brodsky's upcoming performances, and have strong opinions about the musical history of their city. Ryder's language and concerns are everybody's.

But music is not just important as a means of gathering more responsibilities for Ryder. Its primary importance is as the means through which he constructs a language of his

\footnotetext{
${ }^{32}$ Peter Mathews sees the multitudinous interpretive options the novel presents as the antidote to this narrative domination. For Mathews, "the importance of the reader's individual interpretation represents not only a refusal of the tyrant of a single, imposed meaning of a text... it also constitutes an implicit rejection of political totalitarianism, which demands that we follow a fundamentalist understanding of the world. Ishiguro's strategies in The Unconsoled allow him to distort the reader's reality, to turn Ryder's world into an infinite set of variations, thus making the novel a democratic, interpretive performance (both aesthetic and political) of our own" (87).
} 
own, and breaks out of a historical dialogue. Kazan, Mullery, Yashimoto, and all the composers who everyone in the novel seems to have a deep familiarity with, are fictional. So too is the language of his musical terms. Their works, such as Asbestos and Fire, Globe Structures: Option II, and Glass Passions, are made up of "crushed cadences," "vented rests," "fractured time signatures," "elongated discords," and controversial "pigmented triads" $(201,186,491,197)$. For this world in which everything is alien, musical theories also exist in an alternate universe with a private meaning. ${ }^{33}$ This atemporal language holds significance as an illustration of the conflict Ryder is engaged in. A triumph of monoglossia, the terms are entirely defined by Ryder himself within a vacuum. More even than his conversations with his past and future selves, this is truly an instance in which Ryder is having a conversation with himself. This isolated musical language is in fact crucial to Ryder's crisis. In them he becomes an unquestionable authority.

In a similar deviation, in the cinema Ryder identifies the masculine figure of Clint Eastwood rather than Keir Dullea as starring in 2001: A Space Odyssey, one of his "all-time favourite films" (94, 103). Like Ryder's incomprehensible musical vocabulary, this is another instance in which audience attention is being moved from the whirl of the foreign world, onto where the world is coming from. This is not any kind of error by Ishiguro or even Ryder, but a clue into how Ryder's world of crisis operates in its own language of alternative and isolated histories. ${ }^{34}$ Ryder grasps his masculine power by rewriting reality. Through glitches such as this the whole narrative is an effort to get us to stop paying attention to what is going occurring on the level of action ("is Ryder going to make this appointment?") and redirect our focus onto the psychological meaning behind it. What does this anxiety signify, not merely how is it being played out in this circumstance which is ultimately inconsequential. ${ }^{35}$

\footnotetext{
${ }^{33}$ The composer Ned Rorem misses this in his essay on the novel, dismissing this language as "high-sounding gobbledygook" and "as deep as Ishiguro dares go into music. Is it ignorance, poetry, satire? Certainly it is aimless" (64). Sudip Bose responded to the review in The American Scholar, and his response contains a useful question for my reading: "Yes, it may be satirical, it may perhaps be poetic, but only the most literal-minded of readers would find it born out of ignorance. Given what we know about the novel's attention to alternate histories, why shouldn't music theory in this fictional space be based on crushed cadences and elongated discords, in lieu of triadic harmony and sonata form" (Bose)? I would argue Rorem's "literal-minded" understanding, while of course underreading, could be an outcome of interpreting the previous two novels as purely realist fictions, without a distorting masculine crisis.

${ }^{34}$ See Bedggood, who identifies The Unconsoled as the point of transition from Ishiguro's twentieth century work interested in "alternate perspectives" into "his twenty-first-century novels more properly engage[d] with "alternate histories"” (110).

${ }^{35}$ For example, the transposing of Eastwood: with his power to reimagine music and recast movies, Ryder picks for the star of his favourite film the epitome of masculine self-reliance and emotional muteness. The strange inclusion is perhaps evoked later when Ryder recalls the "training sessions" he used to put himself through as a child, in which, upon feeling "a sense of panic and a need for the company of my parents" he would delay and delay his rushing home to find comfort in others, "holding back that moment by an effort of will" (172). The strangulation of his emotional needs is to be found in everything.
} 
In this way music matters very little to the novel. It is significant only to the extent that Ryder has his crisis of masculinity attached to this point of success or failure, but it could be swapped out for a different field in which Ryder might prove himself. Ono's role of artist and Stevens' of butler fit into a similar framework of crisis. In specified historical settings there are particular roles that provide Ishiguro with better positions through which to express the crisis of masculinity and mediate private and public life. But in this ahistorical world this is less significant, and for all three the public role has subsumed the private life and now makes the rules of the world, rewriting what matters. In the rivalry between image and direct experience that Lacan identifies, these narrators experience devastating personal consequences for trying to cram themselves into the shape of the image. This effort at mastery is the action of their masculine crises, and is what emotionally destroys them.

In this world of Ryder's, it is to be music he uses to assert himself and attempts to stave off feelings of crisis in vain. The way out of feeling like his boyhood self letting down his parents, a scene which now takes on uncontainable proportions in Ryder's mind, is to become a master at his craft. At the cost of his relationships and breaking the cycle of familial dysfunction, he succeeds. The surreal status of music in Ryder's storyworld is a proposal in how to make this success worth it. The fantasy Ryder narrates is not a fantasy of fame; it is about imagining a world in which the responsibilities that accompany musical genius, responsibilities that his sense of himself as a man demands he fulfil, would justify what he has done to his family and to himself. We understand the novel to correspond to a different world, one that agrees with our own sense of time and space. This is because, through Ryder's narration and communication of memory, the reader understands that this is a simulation of how Ryder truly experiences the world. Music truly is this important. It is as though there are endless demands made of him, as though he is reminded of his guilt over ruining his parents' marriage through a bad piano performance (his reality) in every young man's face. All the fantastical events of the novel point to a realist psychology that is behind the formulation of this vision. Although he seems to have virtually no control over what is happening to him or how he tells his story, in coming to understand the human behind this nightmare, Ryder's self-authorship is expressed. The haunting glimpses which escape from Ryder's tortuous and endless tasks around the city reveal the storytelling impulse to be something which overwhelms him, something which spills out through the lives of others. Monoglossia, the language of a private world, is the operation Ryder uses in order to live out the truth of his crisis and tell its story. 
The Unconsoled therefore has an intimate connection with the prior novels: its storyworld is the world of masculine crisis. It acts not only as a representation of Ryder's specific crisis, but can be read as a model for the experience of this broader phenomenon. The Unconsoled is Ishiguro's representation of the pyrrhic victory of the narrator within what is in Bakhtin's terms "an intense interaction and struggle between one's own and another's word" (355). For Ono and Stevens, the conflict between a narrator's attempt to assert an individualised language and claim over his world has its limitations built in due to a novel's place in history. But with this novel Ishiguro leans into representing the world as fully a confused synthesis of consensus reality and private anxieties, with history or the past only existing in the form of traumatised memory. The grounds of these crises as control becomes most obvious in The Unconsoled, but it re-contextualises the prior novels as attempts by their narrators to control the narrative and become the source of authority for their worlds. In doing so, Ishiguro breaks his connection to the realist form. 


\section{Conclusion: The Reality of Illusions}

Memory is the dominant process and theme with which Ishiguro's work is associated, and it is that which brings these three novels together most strongly in the representation of masculine crisis. The way memory takes over and changes the present is to be found in every page of The Unconsoled, but in the two previous novels Stevens and Ono also distort reality using their memories again and again. In this way, Ishiguro is a realist of a higher realism. His representations are true not to the observer, but to the world of felt experience. Rather than the complete realist self, identified in the mirror, in this trilogy Ishiguro is loyal to the internal experience of ego and crisis. In fact, with this series of novels what is gradually understood is that traditional realist fiction is not realistic fiction at all. It is through the violation of realism that the truth of experience can be represented. Using this logic, in this thesis I identify unreliability and distortion as a sign of what really matters to these narrators-a truer vision of what is "really going on."

Thus, in these three novels Ishiguro moves towards the narrator being most open about their experience, and this movement means compromising many of the realist features established in his earlier work. A crisis of masculinity is of course a negative manifestation of this victory of the imagination or anxiety, but it is a psychic process which uses the triumph of the imagination to assert itself. Through this trilogy culminating in The Unconsoled, the audience witnesses Ishiguro use masculine crisis as a vehicle to show the way "illusion" (the mental distortions of unreliability) is the key means of representing human life authentically. In Ishiguro's work following this trilogy, When We Were Orphans and Never Let Me Go, he continues this blend of realism and surrealism, but The Unconsoled signifies within Ishiguro's body of work the climax of the approach examined here, and the end of narrators working in a particular way. Cynthia Wong sums up this difference: "In contrast to the narrators of the previous novels who confessed openly to flawed memories and then worked transparently to disclose gaps, even when they were cognizant of efforts to conceal the less flattering aspects of their lives, the narrators here - Banks and Kathy — operate with a more unusual subtlety" (82). The kind of "cognizant" awareness Wong refers to captures something of the connection between self-conscious storytelling and an isolating masculine crisis. 
Bakhtin articulates the impossibility of living life as an absolute individual, as a closed circuit, in what can act as his apotheotic claim about the meaning of shared language: "To be means to be for another, and through the other for oneself. A person has no sovereign internal territory, he is wholly and always on the boundary; looking inside himself, he looks into the eyes of another with the eyes of another" (Problems 287). Bakhtin perfectly expresses here a number of relevant points this thesis has tried to explore. His words can be applied most immediately to the acts of appropriation found through all three of these novels, in which characters take the notion of "look[ing] into the eyes of another with the eyes of another" to the point of literal embodiment. But beyond this technique, Bakhtin's words refocus the meaning of masculinity, which is after all a collection of stories about the self, about how one ought to be and how one ought to live. And it is in this sense that Ishiguro, Bakhtin, and Lacan all demonstrate how one's life involves, and in fact is inconceivable without, the constant intersection and the constant dialogue of others.

As Ryder wanders nameless streets and learns nothing about his situation, Ishiguro demonstrates the truth which the crisis of masculinity denies: meaning is intelligibility, and the only noise which can have no meaning is the purely individual one. With Bakhtin's insight on the shared nature of language, and Lacan's on the creation of the self in others, what becomes clearer is that, while the public world may appear as an unnavigable crescendo of competing responsibilities and haunting guilt, it is in fact the only realm with true resolutory power, and the only world in which one is to be heard out. 


\section{Works Cited}

Adelman, Gary. “Doubles on the Rocks: Ishiguro's The Unconsoled.” Critique: Studies in Contemporary Fiction, vol. 42, no. 3, pp. 166-179.

Bakhtin, Mikhail. The Dialogic Imagination: Four Essays. Edited by Michael Holquist, translated by Caryl Emerson and Michael Holquist. University of Texas Press, 2017.

---. Problems of Dostoevsky's Poetics (Theory and History of Literature). Edited and translated by Caryl Emerson. University of Minnesota Press, 1984.

Bauman, Zygmunt. Mortality, Immortality and Other Life Strategies. Stanford UP, 1992.

Baxter, Leslie. Communication as...: Perspectives on Theory. SAGE Publishing, 2006.

Bedggood, Daniel. "Kazuo Ishiguro, Alternate Histories.” The Contemporary British Novel Since 2000, edited by James Acheson, Edinburgh UP, 2017, pp. 109-118.

Bhabha, Homi. The Location of Culture. London, Routledge, 1994.

Bizzini, Silvia Caporale. "Recollecting Memories, Reconstructing Identities: Narrators as Storytellers in Kazuo Ishiguro's 'When We Were Orphans' and 'Never Let Me Go' / La Recuperación De La Memoria En La Redefinición De La Identidad: La Narración Como Estrategia Literaria En 'When We Were Orphans y Never Let Me Go', De Kazuo Ishiguro." Atlantis, vol. 35, no. 2, 2013, pp 65-80.

Bose, Sudip. "Crushed Cadences and Vented Rests.” The American Scholar, 11 Oct. 2017, https://theamericanscholar.org/crushed-cadences-and-vented-rests/\#.Wd92sMfAK-I.

Bosson, Jennifer K., and Joseph A. Vandello. "Precarious Manhood and Its Links to Action and Aggression." Current Directions in Psychological Science, vol. 20, no. 2, 2011, pp. 82-86. 
Bradbury, Malcolm. The Modern British Novel. $2^{\text {nd }}$ ed., Penguin, 2001.

Broughton, Lynda. "Portrait of the Subject as a Young Man: The Construction of Masculinity Ironized in 'Male." Subjectivity and Literature from the Romantics to the Present Day, edited by Shaw, Philip and Peter Stockwell, Pinter Publishers, 1991.

Case, Alison. Plotting Women: Gender and Narration in the Eighteenth-and NineteenthCentury British Novel. UP of Virginia, 1999.

Chatman, Seymour. Coming to Terms: The Rhetoric of Narrative in Fiction and Film. Cornell UP, 1990.

---. Story and Discourse: Narrative Structure in Fiction and Film. Cornell UP, 1978.

Cheng, Chu-chueh. Margin Without Centre: Kazuo Ishiguro. Bern, Peter Lang, 2010.

Clare, Anthony. On Men: Masculinity in Crisis. Vintage, 2001.

Connell, R. W. Masculinities. $2^{\text {nd }}$ ed., Polity Press, 1995.

Cowie, Elizabeth. Representing the Woman: Cinema and Psychoanalysis. London: Macmillan, 1997.

Dennett, Daniel. "Why Everyone is a Novelist" Times Literary Supplement, 16-22 Sept. 1988, pp. 16-22.

Edwards, Tim. Cultures of Masculinity. Routledge, 2005.

Fairbanks, A. Harris. “Ontology and Narrative Technique in Kazuo Ishiguro’s 'The Unconsoled."” Studies in the Novel, vol. 45, no. 4, 2013, pp. 603-19.

Ferrebe, Alice. Masculinity in Male-Authored Fiction, 1950-2000: Keeping it Up. Springer, 2005.

Fink, Bruce. The Lacanian Subject: Between Language and Jouissance. Princeton UP, 1995. 
François, Pierre. "The Spectral Return of Depths in Kazuo Ishiguro's The Unconsoled." Commonwealth Essays and Studies, vol. 26, no. 2, 2004, pp. 77-90.

Friedlander, Jennifer. Feminine Look: Sexuation, Spectatorship, Subversion. State University of New York Press, 2008.

Gehlawat, Monika. "Myth and Mimetic Failure in 'The Remains of the Day." Contemporary Literature, vol. 54, no. 3, 2013, pp. 491-519.

Hammond, Meghan Marie. “'I can’t even say I made my own mistakes': The Ethics of Genre in Kazuo Ishiguro's The Remains of the Day." Kazuo Ishiguro, New Critical Visions of the Novels, edited by Sebastian Groes and Barry Lewis, Palgrave Macmillan, 2011, pp. 95105.

Holmes, M. Frederick. "Realism, Dreams and the Unconscious in the Novels of Kazuo Ishiguro." The Contemporary British Novel, edited by James Acheson and Sarah C. E. Ross, Edinburgh UP, 2005, pp. 11-22.

Homer, Sean. Jacques Lacan. Routledge, 2005.

Ishiguro, Kazuo. An Artist of the Floating World. Faber and Faber, 2013.

---. A Pale View of Hills. Penguin, 1983.

---. The Remains of the Day. Faber and Faber, 2005.

---. The Unconsoled. Faber and Faber, 2013.

Kemp, Peter "Never Let Me Go by Kazuo Ishiguro" The Times, 20 Feb. 2005 https://www.thetimes.co.uk/article/never-let-me-go-by-kazuo-ishiguro-0v9mbp99jmh.

Koustinoudi, Anna. The Split Subject of Narration in Elizabeth Gaskell's First Person Fiction. Lexington Books, 2012. 
Lacan. Jacques. "Agency of the Letter in the Unconscious or Reason since Freud." Critical Theory Since 1965, edited by Hazard Adams and Leroy Searle. Florida State UP, 1986, pp. 738-56.

Lemon, Robert. "The Comfort of Strangeness: Correlating the Kafkaesque and the Kafkan in Kazuo Ishiguro's The Unconsoled." Kafka for the Twenty-First Century, edited by Stanley Corngold and Ruth V. Gross, Boydell and Brewer Publishing, 2011, pp. 20711.

Lewis, Barry. Kazuo Ishiguro. New York: St. Martin’s Press, 2000.

Mason, Gregory, and Kazuo Ishiguro. “An Interview with Kazuo Ishiguro.” Contemporary Literature, vol. 30, no. 3, 1989, pp. 335-347.

Mathews, Peter. "Variations on a Theme: Performing Ishiguro's The Unconsoled." Interactions, vol. 14, no. 2, 2005, pp. 77-88.

Neagu, Adriana. "International Writing? Kazuo Ishiguro and the Introvert Identities of the Novel." Journal of the English Association, vol. 59, no. 226, 2010, pp. 269-280.

Newton, Adam Zachary. "Telling Others: Secrecy and Recognition in Dickens, Barnes, and Ishiguro.” Narrative Ethics. Harvard UP, 1997.

Ōe, Kenzaburo and Kazuo Ishiguro. "The Novelist in Today’s World: A Conversation,” Boundary, vol. 18, no. 2, 1991.

Park, Seonjoo. “'Spontaneous Mirth’ Out of a 'Misplaced Respectfulness': A Bakhtinian Reading of Kazuo Ishiguro's The Remains of the Day." Ariel: A Review of International English Literature, vol. 39, no. 3, 2008, pp. 45-72.

Petry, Mike. Narratives of Memory and Identity: The Novels of Kazuo Ishiguro. Peter Lang, 1999. 
Phelan, James. "Estranging Unreliability, Bonding Unreliability, and the Ethics of 'Lolita."” Narrative, vol. 15, no. 2, 2007, pp. 222-38.

---. Living to Tell about it: A Rhetoric and Ethics of Character Narration. Cornell UP, 2005.

Ragland-Sullivan, Ellie. Jacques Lacan and the Philosophy of Psychoanalysis. University of Illinois Press, 1986.

Raphael, Linda. Narrative Skepticism: Moral Agency and Representations of Consciousness in Fiction. Fairleigh Dickinson UP, 2001.

Richardson, Brian. Unnatural Voices: Extreme Narration in Modern and Contemporary Fiction. Ohio State UP. 2006.

Rimmon-Kenan, Shlomith. Narrative Fiction: Contemporary Poetics. Routledge, 1990.

Rorem, Ned. Other Entertainment: Collected Pieces. Simon \& Schuster, 1996.

Sacks, Oliver. The Man Who Mistook His Wife for a Hat. Duckworth, 1985.

Salecl, Renata. "I Can’t Love You Unless I Give You Up.” Gaze and Voice as Love Objects: SIC 1, edited by Renata Salecl and Slavoj Žižek, Duke University Press, Durham; London, 1996, pp. 179-207.

Sartre, Jean Paul. Nausea. Translated by Richard Howard. New Directions, 2013.

Scanlan, Margaret. "Mistaken Identities: First-Person Narration in Kazuo Ishiguro.” Journal of Narrative and Life History, vol. 3, no. 2-3, 1993, pp. 139-154.

Schectman, Marya. The Constitution of Selves. Cornell UP, 1996.

Shibata, Motoyuki and Motoko Sugano. “Strange Reads: Kazuo Ishiguro's A Pale View of Hills and An Artist of the Floating World in Japan.” Kazuo Ishiguro: Contemporary 
Critical Perspectives. Edited by Sean Matthews and Sebastian Groes. Continuum, 2009, pp. 20-31.

Stanton, Katherine. “Foreign Feeling: Kazuo Ishiguro's The Unconsoled and the New Europe." Cosmopolitan Fictions: Ethics, politics and global change in the works of Kazuo Ishiguro, Michael Ondaatje, Jamaica Kincaid, and J.M. Coetzee. Routledge, 2006, pp. 9-25.

Suter, Rebecca. Two-World Literature: Kazuo Ishiguro's Early Novels. University of Hawai'i Press, 2020.

Vorda, Allan, et al. “An Interview with Kazuo Ishiguro.” Mississippi Review, vol. 20, no. 1/2, 1991, pp. 131-154.

Walkowitz, Rebecca L. Cosmopolitan Style: Modernism Beyond the Nation. Columbia UP, 2006.

Wall, Kathleen. “'The Remains of the Day' and Its Challenges to Theories of Unreliable Narration." The Journal of Narrative Technique, vol. 24, no. 1, 1994, pp. 18-42.

Weigman, Robyn. "Unmaking: Men and Masculinity in Feminist Theory." Masculinity Studies and Feminist Theory: New Directions, edited by JK Gardiner, Columbia UP, 2002, pp. 31-59.

Westerman, Molly. "Is the Butler Home? Narrative and the Split Subject in 'The Remains of the Day."” Mosaic: An Interdisciplinary Critical Journal, vol. 37, no. 3, 2004, pp. 157-170.

Willer, Robb, et al. "Overdoing Gender: A Test of the Masculine Overcompensation Thesis.” American Journal of Sociology, vol. 118, no. 4, 2013, pp. 980-1022.

Wong, Cynthia F. Kazuo Ishiguro. $3^{\text {rd }}$ ed., Liverpool UP, 2019. 
Wright, Timothy. 'No Homelike Place: The Lesson of History in Kazuo Ishiguro's An Artist of the Floating World." Contemporary Literature, vol. 55, no. 1, 2014, pp. 58-88.

Žižek, Slavoj. The Sublime Object of Ideology. $2^{\text {nd }}$ ed., Verso, 2008. 